Running head: REMEMBRANCE OF THINGS FUTURE

REMEMBRANCE OF THINGS FUTURE: PROSPECTIVE MEMORY IN LABORATORY, WORKPLACE, AND EVERYDAY SETTINGS

R. Key Dismukes

NASA Ames Research Center, Moffett Field, CA 94035 


\begin{abstract}
Prospective memory involves remembering - and sometimes forgetting - to perform tasks that must be deferred. This chapter summarizes and provides a perspective on research and theory in this new and rapidly growing field. I explore the limits of existing experimental paradigms, which fail to capture some critical aspects of performance outside of laboratory settings, and review the relatively few studies in workplace and everyday settings. I suggest countermeasures to reduce vulnerability to forgetting to perform deferred tasks, identify roles for human factors practitioners, and propose a research agenda that would extend our understanding of prospective memory performance.
\end{abstract}




\section{REMEMBRANCE OF THINGS FUTURE: PROSPECTIVE MEMORY IN LABORATORY, WORKPLACE, AND EVERYDAY SETTINGS}

A highly experienced airline crew carefully performs the procedures required to ready the aircraft for takeoff while taxiing to the runway, but discovers a mechanical problem and taxies back to the ramp to get it fixed. When the problem is fixed, the crew taxies back to the runway and takes off. The aircraft climbs only a few feet into the air before the crew loses control and crashes; everyone on board dies. The accident investigation team discovers that the wing flaps had been set to the takeoff position the first time the aircraft taxied out but not the second time. The takeoff configuration warning system, which normally alerts pilots of incorrect settings, failed on this occasion.

A technician is preparing an IV bag with several pharmaceutical ingredients. Just as he is about to reach in a drawer for a vial with the last ingredient, sodium chloride, he is interrupted by another technician's call for assistance on another task. Returning to the IV task a few minutes later he forgets to add the sodium chloride. The IV is administered to a patient who develops severe hyponatremia (a metabolic condition in which low sodium in the body's fluids causes effects ranging from mental dysfunction to convulsions). The problem is detected and corrected several hours later, but the patient's hospitalization is prolonged because of the error.

A university professor decides to drive to a store for milk on a Sunday. On the drive her mind wanders and she discovers herself arriving at the university. She decides to take advantage of being at work to pick up some papers from her office and get the milk on the way home. When she gets home her husband asks, where's the milk, and she realizes she again forgot to go by the store. 
A father agrees to drop his infant at day care on the way to work, normally his wife's task. Recent safety legislation requires that infant carriers be strapped in a rear seat for greater safety in case of collision. The infant falls asleep, and the father is preoccupied with heavy traffic. Forgetting to swing by the day care center, he follows his habitual route directly to work and goes inside, forgetting the child sleeping quietly in the back seat.

What these examples, based on actual events, have in common is forgetting to perform an intended task, typically a task that is not especially difficult or complex. Even the most conscientious individuals are vulnerable to these lapses, sometimes in spite of recognizing that forgetting to act could have fatal consequences. Remembering — and too often forgetting — to perform a task whose execution must be delayed involves prospective memory. Typically the period between forming a delayed intention and the opportunity to execute it is filled with ongoing tasks unrelated to the intention, which is not held in awareness during this period and must be retrieved from memory.

A crucial aspect of prospective memory distinguishing it from most other forms of memory is that no external agent explicitly informs the individual when it is time to stop performing the ongoing task and to retrieve the stored intention from memory- he or she must "remember to remember". The individual is not overtly in retrieval mode, deliberately attempting to retrieve the stored intention. Thus, two of the most central questions of prospective memory research are what cognitive processes work to retrieve deferred intentions at the appropriate time and why they sometimes fail.

Although human memory has been studied extensively for well over a century, only a few papers on prospective memory appeared before 1990, and most of these were about studies conducted under simulated everyday conditions with limited experimental manipulation and 
control. For example, participants might be asked to remind the experimenter to make a telephone call at the end of the experiment—-the challenge being for the participant to remember to perform this delayed task (Harris, 1984) without prompting. However, in 1990, Einstein and McDaniel developed a paradigm (described later) that allowed a wide range of experimental manipulations, as well as repeated measures, and their initial studies stimulated new interest in this topic by many researchers.

By 2009, more than 434 papers with "prospective memory" or "prospective remembering" in the title or abstract appeared in the research literature (Figure 1), and the number of citations of these studies is growing rapidly (Marsh, Cook, \& Hicks, 2006). International conferences devoted to prospective memory research were held in 2000 and 2005, and another conference is planned for 2010. However, even though prospective remembering is centrally involved in many everyday and workplace tasks, a recent search of the journal Human Factors for papers with the term prospective memory or prospective remembering yielded only one paper from 1983 that focused on prospective memory (Wichman \& Oyasato) and another paper from 1998 that used prospective memory as one of several dependent variables in a study of sleep deprivation (Hockey, Wastell, \& Sauer). Six other papers mentioned prospective memory in discussion sections, and various other papers reported studies of topics, such as medication adherence, in which prospective memory undoubtedly plays a role (e.g., Park, Morrell, Frieske, Blackburn, \& Birchmore, 1991). Similarly, only one paper was found in Ergonomics (Dieckmann, Reddersen, Wehner, \& Rall, 2006). Given that prospective memory failures have contributed to many serious accidents in industry and in everyday life (Dismukes, 2008; McDaniel \& Einstein, 2007), this topic deserves the attention of the human factors community. 


\section{(INSERT FIGURE 1 ABOUT HERE)}

In this review, oriented to the human factors community, I will summarize and provide a perspective on recent research and theory on prospective memory. This will not be an exhaustive review of literature, which is already available in two excellent recent books that provide a wealth of detail on the current state of experimental research (Kliegel, McDaniel, \& Einstein, 2008; McDaniel \& Einstein, 2007; also see Brandimonte, Einstein, \& McDaniel, 1996, for a still relevant overview of the field as it was emerging). Rather, I will explore the limits of existing experimental paradigms and theory, which, in my opinion, fail to capture some critical aspects of performance outside the laboratory. I will also review the relatively few studies in workplace and everyday settings and will discuss ways to bridge between these studies and the bulk of experimental research. Finally, I will describe countermeasures that can reduce vulnerability to forgetting to perform intended tasks, and I will propose a research agenda that would extend existing experimental and theoretical approaches and would support human factors practitioners by generating information on a wide range of issues relevant to prospective memory performance in workplace and everyday settings. (For simplicity I will sometimes use the term "real-world" to refer to these and other cultural settings involving tasks and situations not manipulated by the scientists studying them.)

The term prospective memory is a bit misleading; cognitive processes beyond memory are also involved in remembering to perform deferred tasks - for example, goal setting, planning, task management, and attention all play important roles, as will be discussed. Thus, prospective memory is not a unitary cognitive process, but rather is defined by the nature of the task of forming an intention to perform an action at a later time and remembering to perform the intended action at the appropriate time without being explicitly prompted to do so. 
Prospective memory shares some aspects of the broad topic of goals, but with a different focus (Gollwitzer \& Cohen, 2008). Both involve intentionality, determination to bring about some future state. However the focus of one's goals is the outcome state, which may be pursued by various means over time, whereas prospective memory revolves around the intention to perform a specific action. Thus, a prospective memory task might be considered a plan for a specific action to accomplish a goal. Such intentions are ubiquitous in daily life - at the moment a writing pad on my desk lists more than two-dozen actions I wish to remember to accomplish in the near future.

We notice prospective memory mainly when it fails. The content of intentions, what we intend to do, called the retrospective component, is usually simple (e.g., pick up milk on the way home from work), and the most common failure of prospective memory is the failure to remember to act on the intention at the intended time, place, or condition. Less frequently, individuals will realize they intend to do something but cannot retrieve from memory what they intended to do - for example, going into a room to perform some task and failing to remember what the task is. (Little empirical research has addressed forgetting of the content of intentions, presumably because retrospective memory has been studied extensively in the larger literature on memory.) Another way in which the retrospective component sometimes fails is when individuals forget whether they have recently performed a periodic intention such as taking medication. (See Marsh, Hicks, Cook, \& Mayhorn, 2007, for a rare experimental study of this phenomenon.)

\section{Varieties of Prospective Memory}

The primary distinction made in the research literature is between event-based intentions, which are to be performed when a specific situation occurs - for example, an intention to give a 
message to a friend the next time you see her-and time-based intentions, which are to be performed at a specific time-for example, an intention to take cookies out of the oven in 20 minutes. The vast majority of experimental research so far has been directed to event-based prospective memory, with a modest number of studies exploring time-based prospective memory.

Further distinctions within both event-based and time-based prospective memory have sometimes been made. For example, Kvavilashvili and Ellis (1996) distinguished intentions to be executed when an individual is at a particular location from those to be executed when performing a particular activity, and Ellis (1996) divided time-based prospective intentions into two types: pulse, to be executed at a specific time, and step, to be executed during a broader time window. Meacham and Leiman (1976) distinguished habitual remembering of routinely performed intentions, such as brushing one's teeth at a particular time, from episodic remembering of infrequent tasks, such as getting milk on the way home from work, for which one must form a separate intention for each episode. (Episodic tasks can be either event-based or time-based.) In addition to episodic and habitual intentions, Loukopoulos, Dismukes, \& Barshi (2009) identified two other situations in which individuals (specifically, pilots) must remember to perform intended actions: remembering to resume an interrupted task and remembering to switch attention between concurrent tasks. (Table 1 shows one approach to categorizing prospective memory types.)

\section{(INSERT TABLE 1 ABOUT HERE)}

Kvavilashvili and Ellis (1996) argue that not all failures to carry out an intention are errors of prospective memory. In their view, only situations in which an explicit, episodic intention is formed for a delayed task should be considered prospective memory. Thus, 
apparently, they would exclude most habitual tasks, failures to switch attention between concurrent tasks, and interrupted tasks that are not resumed. They would also exclude situations in which individuals absent-mindedly substitute a habitual action for an intended one, for example, going into the bathroom looking for missing eyeglasses and instead brushing one's teeth.

The distinctions Kvavilashvili and Ellis make are important for understanding why people forget to do what they intend, but I prefer to group all these phenomena under the umbrella of prospective memory. When people inadvertently fail to perform an intended action in these diverse situations, they think of themselves as having forgotten. Further, these diverse situations share some common features. The important thing, especially for the human factors community, is not to worry too much about semantics but to understand the diverse phenomena involved in forgetting to perform intended actions in prototypical situations so that we can develop countermeasures to reduce vulnerability to these errors.

All varieties of prospective memory involve the three stages of all memory processes, although the way in which the stages operate may vary substantially among varieties:

1) Encoding, in which the intention to act at a later time is formed. Encoding may or may not precisely specify the conditions under which the action is to be performed, but these conditions are at least implicit. These conditions constitute a window of opportunity to execute the deferred intention, which may be narrow or broad. For example, you might encode an intention to return a library book tomorrow morning while walking to work, but, alternatively, might encode the intention to return the book sometime before it is due at the end of the month.

2) Retention, which may vary greatly in duration, and which is typically filled with one or many ongoing tasks, mostly not related to the deferred intention. These ongoing tasks occupy attention 
and working memory, so that in most situations the individual does not maintain continual awareness of the deferred intention.

3) Retrieval, in which the deferred intention is retrieved from memory into awareness.

\section{Event-based Prospective Memory}

In 1990, Einstein and McDaniel published a prospective memory study using a laboratory paradigm that stimulated research worldwide. In this paradigm, participants are given instructions for an ongoing task such as rating the pleasantness of a series of words appearing on a computer screen. They are also given an additional task involving prospective memory; for example, whenever they encounter a particular word (e.g., dog) during the ongoing task they are to perform an additional action, such as pressing a special key. (Thus "dog" is called the target cue. In some cases the additional action is to be made in response to any word of a particular category, such as “animal”.) Typically the retention interval between instructions and encountering a prospective memory target word is around 5-10 minutes, and spacing of prospective memory trials within an experiment ranges from less than a minute to several minutes. (The relation of the paradigm's features to the range of prospective memory conditions in real-world situations will be discussed later.) When questioned after the experiment, participants have little difficulty recalling the prospective response they were supposed to make and the condition for making that response, even though they forget to make the response on some or many trials. Although it may seem surprising that participants would forget to perform such a simple deferred task, this parallels everyday experience, and error rates in this paradigm are high enough to allow systematic manipulation. Using variations on the Einstein-McDaniel paradigm, scientists have elucidated many aspects of the cognitive processes of encoding, retention, and retrieval underlying prospective memory. Since a central concern in prospective 
memory is failure to retrieve and act on intentions, I will start with studies of retrieval. (See Table 2 for a list of variables shown to affect prospective memory performance.)

\section{(INSERT TABLE 2 ABOUT HERE)}

\section{Retrieval}

Prospective memory performance is greatly affected by the relation of the target cue (that signals the opportunity to execute the deferred intention) to the content of the intention stored in memory. Cues that are strongly associated with the intention are more effective in eliciting retrieval (McDaniel, Guynn, Einstein, \& Breneiser, 2004; Loft \& Yeo, 2007). This is illustrated by studies in which the prospective response is to say a particular word when the target cue occurs in the ongoing task. For example, if the target cue is the word church, performance is much better when the intended prospective response is to say "steeple" than when the response is "sauce". Apparently the strong pre-existing association between church and steeple increases the amount of activation that spreads from the encountered target cue to the associated response stored in memory, facilitating retrieval. (Activation is a cognitive psychology concept used to characterize the level of accessibility of items stored in memory. More highly activated items are more readily accessible and can be retrieved more quickly. One theoretical perspective holds that items held in awareness provide activation to other items associated through experience and stored as memory, and this process supports retrieval of information needed for task performance (Anderson \& Lebiere, 1998).

Cues that are distinctive, salient, or unusual produce better prospective remembering than cues that are less so (Brandimonte \& Passolunghi, 1994; Einstein, McDaniel, Manzi, Cochran, \& Baker, 2000; Uttl, 2005). One example is target words printed in all capitalized letters occurring in a series of uncapitalized words; another example is target words seldom encountered, such as 
monad. The features of such targets are assumed to attract attention and thus elicit more extensive processing, which provides additional activation to items associated in memory. For example, the word appearing in capitalized letters might cause the participant to pause to wonder why it is different from the other words in the ongoing task. Also, unusual words have fewer preexisting associations in memory to dilute the spread of activation from the target cue to the deferred intention with which it is associated.

The way in which the ongoing task causes potential target cues to be processed greatly affects prospective remembering. For example, participants might be given the ongoing task of naming famous people viewed in a series of photographs and an additional task of pressing a certain key when the name John is identified (in one condition) or pressing the key when a man with a pipe is identified (in another condition) (Maylor, 1993). Performance is better in the first condition, presumably because the ongoing task causes the participant to focus explicitly on the aspect of the target directly related to how the prospective task is framed in memory. In this condition the prospective memory target cue is said to be focal to the ongoing task. In the second condition the ongoing task does not require the participant to think about whether the persons in the photographs have pipes, thus this target cue is said to be non-focal.

In addition to the target cue itself, the context of the ongoing task may support retrieval of intended actions (Cook, Marsh, \& Hicks, 2004; Nowinski \& Dismukes, 2005). Participants better remember to perform delayed tasks when the target cue is encountered in the context of an ongoing task associated with the delayed intention during encoding than when the target is encountered in a different context. Thus, an individual would be more likely to remember an intention to give a work-related message to a colleague when the colleague is encountered at work than when the colleague is encountered at a grocery store. 
Prospective remembering usually suffers when the cognitive demands of the ongoing task are high. Dividing attention between two ongoing tasks (McDaniel \& Einstein, 2007, p. 63) or increasing the rate of ongoing task demands (Stone, Dismukes \& Remington, 2001) typically impairs prospective memory. Marsh and Hicks (1998) cleverly demonstrated that this impairment occurs when ongoing tasks make high demands on the executive component of working memory but not when the demands are on the other two components, the visual-spatial sketchpad and the phonological loop. (The phonological loop allows verbal information to be maintained and manipulated through short-term processes such as rehearsal. Similarly, the visual-spatial sketchpad allows visual and spatial information to be readily accessible and manipulated for short periods.) An important exception to the typical results with highly demanding ongoing tasks occurs when the target cue is highly salient (Einstein, McDaniel, Manzi, Cochran, \& Baker, 2000) or highly associated with the prospective response (McDaniel, Guynn, Einstein, \& Breneiser, 2004). In these two situations prospective remembering is not impaired even when the ongoing task places severe demands on executive processes.

Competing theoretical accounts of retrieval. Examining theoretical issues will help make sense of the experimental findings just discussed. Currently, the most contentious theoretical issue in prospective memory research concerns how delayed intentions are retrieved into awareness. How this issue is resolved will shed light on why we are vulnerable to forgetting to perform deferred intentions and on the factors affecting this vulnerability; it will also point to ways to create practical countermeasures to reduce vulnerability. (However, readers less interested in theoretical aspects can skip to the next section without losing the plot of this chapter.) 
One theoretical perspective (Guynn, McDaniel, \& Einstein, 2001; McDaniel, RobinsonRiegler, \& Einstein, 1998; Dismukes \& Nowinski, 2006) argues that the process is automaticencountering target cues triggers retrieval of intentions through a reflexive associative process that requires few, if any, limited cognitive resources (working memory and attention). When the target cue is encountered, its association in memory with the deferred intention provides sufficient activation for the intention to either be retrieved directly into memory or for the participant to recognize that something is special about this cue, triggering a directed search of memory. This view is consistent with the everyday experience of having intentions pop back into awareness without conscious effort. It is also consistent with Reese and Cherry's (2002) finding that participants probed during ongoing tasks reported rarely thinking about the prospective task while performing an ongoing task and that infrequent thoughts about the prospective task were not correlated with prospective memory performance.

Several lines of experimental evidence support the automatic association view, including the previously cited studies showing that divided attention does not impair prospective remembering when target cues are distinctive or highly associated with the intended action. Other studies have shown that intentions are activated even when encountering target cues in situations in which participants do not intend to respond, suggesting an automatic, or spontaneous response (Einstein, McDaniel, Thomas, Mayfield, Shank, Morrisette, \& Breneiser, 2005; Holbrook, Nowinski \& Dismukes, 2005). Also, in diary studies (Kvavilashvili \& Fisher, 2007) and in workplace studies (Sellen, Louie, Harris \& Wilkins, 1997) participants report thoughts of delayed intentions coming into mind during periods of low activity long before the time when the intention is to be executed. 
In direct contrast to the automatic association perspective, Smith and colleagues argue that retrieval of delayed intentions always requires limited cognitive resources (Smith, 2003; Smith \& Bayen, 2004; Smith, Hunt, McVay, \& McConnell, 2007). They designed an ingenious paradigm to test this hypothesis. Participants are given the ongoing task of performing lexical decisions on a series of short letter-strings presented on a computer screen: Is the target letterstring a word or not? (Called the lexical decision task, LDT.) The prospective task is to make a separate response to certain words, but the crucial measure is whether having this prospective task slows responding to the lexical decision task on trials in which the prospective target does not occur. Slowing on these trials is taken to indicate that being prepared to perform the prospective task requires limited cognitive resources in competition with the ongoing task, which is what Smith and colleagues found. They developed a formal mathematical model—Preparatory and Attentional Memory Process (PAM) — asserting that individuals must maintain a preparatory attentional state to detect and evaluate potential cues indicating opportunities to execute delayed intentions. Intentions cannot be retrieved when this preparatory state is not operating. The exact nature of this preparatory state has not been defined beyond requiring both attentional and memory processes, although Smith et al. (2007) assert that it can operate outside the threshold of awareness.

Smith and colleagues have provided convincing evidence that being prepared to execute a delayed intention taxes limited cognitive resources in their paradigm. The unresolved issue is whether successful execution of delayed intentions always requires limited resources—especially in everyday situations in which retention intervals are typically much longer, ongoing tasks are more heterogeneous than in laboratory paradigms, and multiple, closely-spaced trials are rarely if ever encountered. McDaniel and Einstein (2000) proposed a multiprocess theory, combining 
aspects of the automatic association view and the view that prospective remembering draws upon limited resources (which they term strategic monitoring). They assert that in some situations individuals rely on automatic retrieval processes but in others devote resources to strategic monitoring to improve performance. (One can argue that automatic associative processes are always in operation, but individuals may voluntarily supplement those processes.)

Consistent with the multiprocess theory, studies have shown that participants allocate more or fewer resources (as measured by cost to lexical decision-making speed) to prospective remembering as a function of the relative importance of the prospective memory and ongoing tasks (Kliegel, Martin, McDaniel, \& Einstein, 2001, 2004). When instructions to participants emphasized the importance of the prospective task, lexical decisions slowed, suggesting some resources were shifted to that task. However, emphasis of the prospective memory task improved performance only if the target cue was non-focal; if the cue was focal, performance did not improve, suggesting that in the focal condition retrieval is automatic and does not benefit from additional resources. Similarly, Marsh, Hicks, and Cook (2005) found that instructions to increase effort toward the ongoing task speeded lexical decision-making, but impaired prospective memory performance only when the prospective task competed for the same cognitive resources as the ongoing task.

As Marsh et al. (2005) suggested, participants' attention toward both ongoing and prospective tasks probably waxes and wanes over time, and this variation is undoubtedly much greater outside of laboratory situations. Loft and Yeo (2007) capitalized on this natural variation, looking at lexical decision-making speed on trials shortly before a prospective target cue appeared, for indication of lapses in monitoring. On trials in which monitoring for prospective memory targets had apparently lapsed — as evidenced by lack of slowing of lexical decision- 
making - prospective remembering was not affected if the target cue was highly associated with the prospective response (e.g., the cue was mouth and the response was to say wash). However, if the cue and response were not highly associated (e.g., mouth and table), prospective remembering suffered when monitoring lapsed. This study suggests that monitoring for prospective cues varies naturally and contributes to prospective remembering in some situations but not in others. Marsh, Cook, \& Hicks (2006) further suggested that allocation of attention between ongoing tasks and prospective tasks is dynamic and flexible, though the studies cited above indicate that prospective memory performance is correlated with attention allocation only in some situations.

The multiprocess theory appears to reconcile seemingly contradictory experimental findings. One possible explanation for conflicting results with studies of interference with ongoing task performance (when lexical decision-making speed is the dependent measure) lies with differences in details of the experimental paradigm, which affect how participants deploy limited cognitive resources. Currently, the preponderance of evidence supports the multiprocess perspective that automatic processes allow successful prospective remembering in some situations and that individuals supplement these processes with limited cognitive resources to improve performance in other situations. However, the issue is not completely resolved (Smith et al., 2007); Einstein and McDaniel (in press) suggest ways new experimental designs might settle the controversy.

I devoted a fair amount of space here to these theoretical issues both because they help us understand experimental findings and because they lead us to think about practical implications. McDaniel and Einstein $(2000,2007)$ do not assert that prospective remembering is ever completely automatic, but rather that in some situations it is largely automatic and in other 
situations successful performance requires appreciable commitment of limited resources (strategic monitoring). It seems likely that automaticity is not all-or-nothing but a matter of degree, especially in situations involving the complex tasks of the workplace and daily living. If the multiprocess theory is correct, one practical issue is how to enhance automatic retrieval of intentions at the appropriate time. Another practical issue is what real-world situations require some sort of monitoring or preparatory attentional state to achieve adequate prospective remembering. How big a role does monitoring play in everyday situations in comparison to other factors, such as cue salience and implementation planning?

If, as Smith and colleagues assert $(2003,2007)$, a preparatory attentional state must always be established in order for a delayed intention to be executed, it is crucial to determine the nature of this preparatory state and what factors elicit and maintain it. Also, we need to know how costs to lexical decision-making extend to performance of diverse ongoing tasks outside the laboratory. Could the preparatory processes Smith et al. propose be maintained for days and weeks while a series of ongoing tasks are performed and multiple intentions are deferred? Typically lexical decision-making is slowed by fractions of a second-would performance of realworld tasks be affected appreciably, and, if so, in what manner? And do different levels of cost (say $50 \mathrm{msec}$ versus $150 \mathrm{msec}$ ) imply differences in cognitive resources involved in performing the prospective memory task? (Practical implications of laboratory findings will be treated at greater length in later sections.)

\section{Encoding}

Consider some of the diverse ways in which we form intentions in our daily lives. I may determine to ask a friend for a favor whenever I next see him, or may identify a specific meeting time and place at which to ask. I may decide to add a footnote to this paper after finishing the 
first draft and assume that I will do this while working on the desktop computer in my office, even though I may end up doing my revisions on my laptop while traveling. You may decide to surprise your spouse with a birthday gift, an intention that will entail sub-ordinate goals: what kind of gift, where and when to buy it, how to hide it until the birthday, and so forth. You may engage in the substantial planning necessary to execute all aspects of this intention at the time you form it, or you may plan each aspect separately over time.

Contrast this diversity with the Einstein-McDaniel paradigm, in which intentions are given to participants in the form of instructions, rather than being self generated. Participants are told to execute a delayed intention when and only when a specified discrete event occurs, and typically this event occurs several times in the course of the experiment. In most experiments the participant performs only a single ongoing task (although divided attention or task switching are occasionally involved), in contrast to everyday situations in which individuals maintain multiple delayed intentions while performing diverse ongoing tasks that change dynamically. Individuals often do not know what task they will be performing when the opportunity to execute the delayed intention arrives. Little research has addressed how these differences between typical laboratory paradigms and everyday prospective memory situations might affect performance.

The diversity of intentions in everyday life, and the ways in which individuals plan to execute those intentions (Holbrook \& Dismukes, 2009) has not been explored in depth, and, in comparison to retrieval, relatively little is known about encoding of intentions. An important exception comes from studies in the field of social psychology (Cohen \& Gollwitzer, 2008). Noting that in everyday life people's plans to perform delayed intentions are often quite vague about the circumstances under which the intentions are to be performed, social psychologists developed the concept and technique of implementation intentions (Golwitzer, 1999). Typically, 
the intention is a personal one in everyday life; the manipulation in these studies is to instruct one group of participants to determine the specific situation in which they will execute the delayed intention, to identify specific cues they are likely to encounter at that time, and to associate those cues with the intention through rehearsal and/or visualization. For example, the implementation intention for individuals wanting to remember to take a medication daily might be to visualize themselves taking the medication in the bathroom immediately after brushing their teeth in the morning.

Forming implementation intentions has been shown to greatly improve prospective remembering in diverse everyday tasks such as exercising (Milne, Orbell, \& Sheeran, 2002), breast self-examination (Orbell, Hodgkins, \& Sheeran, 1997), medication adherence (Sheeren \& Orbell, 1999; Wilson \& Park, 2008), and completing homework assignments (Gollwitzer \& Brandstatter, 1997). In some studies, implementation intentions improved prospective memory performance by two to four-fold.

Implementation intentions are argued to improve performance by creating a link in memory between potential environmental cues and the delayed intentions, by making this link more accessible in memory, and by allowing environmental cues to trigger retrieval in an automatic fashion that makes few demands of limited cognitive resources (Gollwitzer, 1999; Cohen \& Gollwitzer, 2008). As yet, little experimental research has been directed to exploring these theoretical assertions (McDaniel \& Einstein, 2007, p 117). One reason these intriguing and important studies have received limited experimental investigation is that most prospective memory experimental paradigms are not well designed for this investigation. A sort of implementation intention is already built into the Einstein-McDaniel paradigm — participants are 
told what the ongoing task will be and are told to respond to a specific target cue or category of cue, thus limited manipulation is possible.

Some, though not all, laboratory studies have found that elaborating standard prospective memory instructions in the form of implementation intentions enhances prospective remembering (Chasteen, Park, \& Schwarz, 2001; Cohen \& Gollwitzer, 2008; McDaniel, Howard, \& Butler, 2008). These studies support the argument that implementation intentions improve automatic retrieval of intentions by increasing the association in memory between target cues and deferred intentions. However, the picture is more complex than this might suggest. Meeks and Marsh (2010) found that forming implementation intentions improved prospective remembering with category target instructions (e.g., respond to any animal name). With this prospective memory task, participants would not have been able to increase the association between the intention and specific target cues (e.g., dog), so the authors argued that forming implementation intentions in this situation must improve prospective remembering by some other mechanism, perhaps by increasing the importance of the prospective memory task and thus altering attention allocation. Nevertheless, the research evidence is clear that implementation intentions provide a powerful and practical way to improve prospective memory performance, regardless of the underlying mechanisms.

Kliegel and colleagues have developed a sub-goal scheduling task that allows some aspects of intention planning to be studied experimentally (Kleigel, McDaniel, \& Einstein, 2000; Kliegel, Martin, McDaniel, \& Einstein, 2002). Participants must switch among sub-tasks strategically to obtain a good score, and they must remember to make these switches at the appropriate circumstance even though engaged in a cognitively demanding ongoing sub-task. Consistent with the concept of implementation intentions, studies with this paradigm show that 
remembering to switch improves with the quality of planning (identifying in advance specific conditions for switching) and with the degree of plan adherence during task execution. In addition to supporting study of implementation planning, this scheduling paradigm could be used to study concurrent task management, discussed in a later section.

In summary, the limited research to date on encoding of deferred intentions suggests that this is a topic that could support developing practical measures to improve prospective remembering.

\section{Retention}

In the interval between forming an intention and the opportunity to execute it we typically turn our attention to other tasks, thus the intention must be stored in memory and later retrieved. What is the status of the stored intention during this retention interval and how does its status affect the probability of retrieval? Does this status change over time, and if so in what way? The answers to these questions are not yet clear, but they will probably vary as a function of how the intention is encoded, its relation to ongoing tasks, cues encountered during retention that may be related to the intention, and strategies individuals use to remember to perform the intention. These questions are directly relevant to the central issue of how deferred intentions are retrieved at the appropriate time. Although we are all frustrated when we fail to remember to perform intentions, in a way it is remarkable that we do succeed so often, given that ongoing tasks demand our attention, and it is not practical to continuously ask ourselves "Is there something else I should be doing now?"

One suggestion, originally put forward by Miller, Galanter, and Pribram (1960), is that intentions have some sort of special status in memory that makes them more accessible, easier to retrieve than other memory items. A prominent concept in cognitive psychology is that memory 
items lie along a continuum of activation, and that accessibility is a function of the level of activation (Anderson, 1996). If memory for intentions were more highly activated than comparable memory items not associated with intentionality, environmental cues might more readily trigger retrieval of intentions into awareness, especially when individuals rely on automatic retrieval.

One line of experimental investigation, started by Goschke and Kuhl (1993) supports this suggestion. In this paradigm, as modified by Marsh, Hicks, and Bink (1998), activation/accessibility of the retrospective component of prospective memory is measured by how quickly participants can perform a lexical decision task. Participants memorize a pair of action scripts, each pair consisting of several phrases such as set the table, pour the coffee, sharpen the pencil; each script is organized around a specific theme. After memorizing, participants are told that they will be expected to perform one of the pair of action scripts, which (after it is identified as such) becomes a prospective script, but not the other, which then becomes a neutral script. Participants next perform an LDT in which they encounter a series of words and non-words; a small subset of the LDT words were memorized in the prospective script and another small subset were memorized in the neutral script. Studies consistently show an intentional superiority effect (ISE) in which words from the prospective script are responded to more quickly than words from the neutral script, indicating greater activation or accessibility of the script that participants intend to perform (Goschke \& Kuhl, 1993; Marsh, Hicks, \& Bink, 1998; Marsh, Hicks, \& Byran, 1999).

Note that, although the prospective script involves intentionality, the Goschke and Kuhl paradigm does not present a true prospective memory situation because participants expect to be told when to execute the prospective script rather than having to self-initiate it without 
prompting. However, Dockree and Ellis (2001) modified the paradigm o that participants did expect to have to remember to perform the intended actions without prompting. In this study, after being given instructions for two tasks supposedly to be performed at the end of a cover experiment, participants were later told one of the tasks was no longer needed and they would only have to perform the other task. When given a LDT, participants responded more quickly to words from the task still to be performed than to words from the cancelled task.

It would seem unnecessary, perhaps maladaptive, for intentions to remain in an activated state after they have been performed. To explore this issue, Marsh et al. (1998) compared LDT performance when action scripts that had recently been performed were used to LDT performance when action scripts yet to be performed were used. They discovered that the intention superiority effect disappeared after performing an action script, and in fact was reversed-lexical decision making was significantly slowed (in comparison to neutral script words) after completion of a prospective script, suggesting that this script was now inhibited rather than activated. Conceivably this inhibition is a mechanism to prevent completed intentions from intruding into our thoughts when no longer relevant.

Although ISE studies are quite valuable in helping us understand some aspects of the cognitive mechanisms that may underlie prospective memory, the limitations of these studies should be noted. Although it is plausible that heightened activation of the content of intentions supports prospective remembering, this has not yet been demonstrated experimentally, and the cognitive mechanism(s) producing this activation have not yet been demonstrated. The ISE has been studied only for retention intervals of no more than 30 minutes, so it is not known if heightened activation would persist for the much longer intervals often required in many everyday prospective memory tasks. More broadly, we do not know how heightened activation 
would operate in everyday life in which we juggle many goals and subgoals concurrentlywould all intentions be maintained in heightened activation?

Diary studies and studies in actual workplace settings provide another form of insight into the status of prospective memory during retention. Kvavilashvili and Fisher (2007) asked participants to make a telephone call to the experimenters at a particular time seven days later (a time-based task) or when they received a certain text message (an event-based task, which also occurred a week later). Participants kept diaries in which they recorded instances in which the intention came to mind during the week. They also recorded what they were doing when the intention came to mind and what seemed to trigger retrieval of the intention. The average number of recollections per participant over the week ranged from about eight to about 11 in the three experiments. (Of course, the act of keeping a diary may have kept the intention to make the telephone call closer to mind during the week.)

Recalling the intention was often triggered by chance encounters with environmental cues thematically related to the intention (e.g., seeing a telephone, diary, or watch). Somewhat less frequently, recall was triggered by a participant's stream of thought (e.g., thinking about other intentions), and much less frequently was recall a response to self-initiated planning thoughts (e.g., thinking about tasks to be performed that day). Strikingly, between a fourth and a half of the recollections occurred without any apparent trigger — the thought of calling the experimenter seemed to just pop into mind. Kvavilashvili and Fisher interpreted these results as suggesting that the representation of the intention remained activated at a sub-threshold level throughout the week, increasing the ability of chance cues to trigger retrieval. In contrast, deliberate search of memory for what to do next did not seem to play a major role. Sub-threshold activation does not imply maintenance of a preparatory attentional state, because it would not 
necessary draw on limited resources, however this does underscore the question of how a preparatory state might be maintained.

Kvavilashvili and Fisher also found that intention retrieval during the week was more likely to occur when participants were engaged in relatively automatic tasks making low demands on attention. Also, in contrast to laboratory studies cited previously, an importance manipulation had no effect on retrievals during the week or on prospective memory performance, highlighting the need for caution in extrapolating from laboratory studies to diverse real-world tasks.

Sellen, Louie, Harris, and Wilkins (1997) reported an ingenious study of retention-period recall in which participants performed an event-based prospective task and a time-based task in their own office workplace, using identity badges already in use that recorded the location of the participant whenever a button on the badge was pressed. In the event-based task, participants were told to press the button three times whenever they entered the "commons", a shared work area, and to press the button once any time they thought of this intention any time during the week. On a different week, participants were told to press the button three times at three specified times during the day and to press the button once whenever they thought of this timebased task.

As participants approached the commons, the frequency of intention recall increased substantially, especially in the last 30 seconds; when they left the commons recall dropped off markedly for a period. However, this pattern occurred only when participants successfully remembered to press the badge button three times when inside the commons. When they failed to remember, the rate of single-button presses did not rise as they approached the commons, but often did go up immediately after exiting the room. These results suggest that environmental 
cues contribute both to successful performance and to retrieving an intention after leaving the window of opportunity to execute it, but these cues are not sufficient to guarantee performance.

The rate of intention retrieval also increased when participants were in transition locations, such as stairwells or hallways, when task demands were presumably lower. This is consistent with Kvavilashvili and Fisher's (2007) finding that retrieval of intentions was more frequent with less attention-demanding tasks. It may be that when ongoing tasks do not completely occupy attention and working memory, random variations in activation allow thoughts of other goals and tasks to emerge. Alternately, individuals may develop the habit of using low workload periods to deliberately search memory for other things they must accomplish.

Few experimental studies have examined how variations in tasks during the retention interval might affect prospective memory performance. Hicks, Marsh, and Russell (2000) found that prospective memory performance increased significantly when breaks occurred in retentioninterval tasks, and even more so when those breaks did not make task demands at all. Performance was also better when participants switched among tasks during this interval. In contrast, Finstad, Bink, McDaniel, \& Einstein (2006) found the opposite- - both breaks and task switching impaired prospective remembering. However, in this study the breaks occurred during the ongoing task, when participants knew they might encounter prospective memory targets, whereas in the Hicks et al. study the breaks occurred during the retention interval, when targets would not be encountered. It may be that participants used different strategies for attention allocation for an ongoing task combined with a prospective memory task than for the single task during the retention interval. These different strategies might affect thinking about and activation of the prospective memory task. 
In both the Sellen et al. (1997) study and the Kvavilashvili and Fisher (2007) study, prospective memory performance was worse on the time-based task than on the event-based task, even though frequency of thought about the time-based intention was greater. This may reflect participants' recognition that the time-based task was more difficult (because they are less likely to encounter environmental cues during the window of opportunity), and an attempt to compensate with rehearsal during the retention interval.

Does the frequency of retrieval of an intention before the window of opportunity to execute it affect the probability of successfully remembering to execute the intention when the opportunity arrives? These retention-interval recollections might serve to increase activation of the intention and might elaborate the original encoding of the intention. Alternately, the increased activation might subside before the window of opportunity for execution, and encoding might not be the factor limiting successful remembering to perform the intention. Unfortunately, few data exist to answer this question. Prospective memory performance in the Kvavilashvili and Fisher (2007) study was at ceiling, and Sellen et al. (1997) did not report analyzing correlation of retention-interval recollections with performance. However, Kvavilashvili and Fisher did report a significant correlation (0.39) between frequency of recollections and the percent of intentions fulfilled on time, rather than late.

Does prospective remembering show decay over time and, if so, does this decay resemble the classic decay curve prominent in studies of retrospective memory? Surprisingly, only a handful of studies have examined this question, using diverse experiment designs, and the results are inconsistent. Stone, Dismukes, and Remington (2001) found no differences in retention intervals of one, three, and five minutes. Einstein, Holland, McDaniel, and Guynn (1992) found no difference in prospective remembering between 15 minutes and 30 minutes, and Guynn, 
McDaniel, and Einstein (1998) found no difference between four and 20 minute intervals. In contrast, Brandimonte and Passolunghi (1994) found prospective remembering declined from zero to three minutes if the retention interval was filled with a demanding mental task or undemanding motor activity, but not with undemanding verbal activity. Hicks, Marshall, and Russell (2000) found that prospective remembering actually improved from a 2.5 minute interval to a 15 minute interval, however this result must be interpreted with caution because the ongoing task during the longer interval was not the same as the one used with the shorter interval. Holbrook, Nowinski, and Dismukes (2005) found that activation of a completed intention (as measured by decreased reaction time on an unrelated speeded task) was decreased after a 40 minute delay, compared to a five minute delay.

In a special case of retention, Einstein, McDaniel, Williford, Pagan, and Dismukes (2003) examined prospective remembering when participants had to delay executing a successfully retrieved intention for a short period (called the delayed-execute paradigm). Delays of as little as 5 seconds caused small but significant reduction in performance, however performance did not decline further at 15 or 40 seconds. These results illustrate that in some situations prospective remembering is quite fragile.

The studies just cited used laboratory paradigms and short retention intervals. Nigro and Cicogna (2000) used a task more representative of some everyday situations - remembering to give a message to a second experimenter-and found prospective remembering to not differ between 10 minute, two-day, and two-week intervals.

Almost certainly these diverse findings reflect differences in methodology, especially differences in ongoing tasks during the retention interval that differ in cognitive demand, opportunities for rehearsal, and relation between the ongoing task and the prospective task. The 
field would benefit from more systematic study of retention interval, one of several areas of study that could help us elucidate the diverse ways in which deferred intentions are stored in memory and retrieved.

\section{Time-based Prospective Memory}

In some situations we must remember to perform an intention at a particular time- - for example, going to an appointment—or after a specific interval, for example, taking cookies out of the oven after the intended cooking time. Theoretically, time-based prospective remembering should hinge on quite different mechanisms than event-based remembering, because external cues are not available to trigger retrieval. In reality, incidental cues often remind individuals of a time-based intention, as reported by Kvavilashvili and Fisher (2007). Also, individuals may deliberately convert a time-based task to an event based one, for example, by setting an alarm, creating reminder cues likely to be noticed at the appropriate time, or associating the time-based task to an event—-for example, noting that a planned telephone call at 10 o'clock can be made immediately after a class ends (Graf \& Grondin, 2006). Nevertheless, it is important to explore the mechanisms underlying time-based remembering in the absence of external cues.

Relatively few laboratory studies have examined time-based remembering (see Glicksohn \& Myslobodsky, 2006, for a collection of essays on the topic). Typically, participants are given an ongoing task and told that they should also make a separate response at periodic intervals (which may vary in duration or be fixed). Participants do not have direct access to time information, but can look over their shoulder (Harris \& Wilkins, 1982) or press a computer button (Einstein, McDaniel, Richardson, Guynn, \& Cunfer, 1995) to see a clock. Typically, participants increase frequency of clock-checking as the target time approaches, and on trials in which this increase does not occur they are less likely to respond at the target time. This pattern 
of monitoring has been interpreted as evidence that participants are using an iterative Test-WaitTest-Exit strategy in which early tests tell them how much longer until a response is needed (Harris, 1984). Frequency of monitoring increases as the target time approaches and more precision is needed to insure a timely response. This strategy would presumably draw upon internal biological processes that allow approximate but not precise estimates of time.

Arguably, maintaining this sort of monitoring is more demanding of limited cognitive resources than relying on target cues to trigger retrieval in event-based prospective remembering. In support of this view, older participants, whose working memory capacity is typically diminished, do not show a pronounced increase in monitoring as the target time approaches and generally perform more poorly in most laboratory paradigms than younger participants, particularly if the ongoing task is demanding (Einstein et al., 1995; d'Yderwalle, Bouckaert, \& Brunfaut, 2001).

In contrast with these laboratory findings, older participants often show unimpaired or even improved time-based prospective remembering in paradigms, such as that of Kvavilashvili and Fisher (2007), involving actual everyday situations. Possible explanations for the good performance of older adults in these paradigms are (1) they encounter happenstance cues in their home settings that remind them of the time-based intention during the much longer retention intervals of these paradigms, (2) they create cues to remind themselves, (3) the daily tasks of older adults are less demanding, allowing more opportunities for retrieval and (4) they may consider tasks such as taking medication more important to their health than do younger individuals. It is also relevant that, in event-based laboratory paradigms in which participants are likely to rely on spontaneous (automatic) retrieval rather than engaging in effortful monitoring (e.g., when the target is a single, salient cue), older adults perform as well as younger 
participants (McDaniel, Einstein, \& Rendell, 2008). Thus, if older adults convert time-based tasks to event-based tasks in everyday situations by using external cues they may perform as well as younger adults.

It is important to note that the intervals used in laboratory studies of prospective remembering are quite short, typically only a few minutes, in contrast to the much longer intervals in diary studies and everyday experience (Holbrook \& Dismukes, 2009). It seems highly improbable that individuals would maintain a continuous monitoring strategy for long intervals when engaging in diverse ongoing tasks, however the mechanisms underlying retrieval after long intervals have not been explored in depth. Kvavilashvili and Fisher (2007) found that the mean number of intention retrievals over the seven days of their study formed a U-shaped curve, with a relatively high rate of retrieval on the first day, diminishing to a low rate at midweek and reaching a maximum on the day participants were to call the experimenter. This pattern occurred only for participants who remembered to make the call at or near the specified time; participants who were late making the call (all remembered eventually) did not record an increase in retrieval rate on the day to make the call. These results might be explained as follows: As the target time approaches, most participants respond to each retrieval by additional processing of the retrieved intention, increasing activation and making future retrievals more likely, causing the retrieval rate to snowball toward the end. It is also possible that, as the target time gets very close, participants shift to a continuous monitoring mode.

In everyday and workplace settings prospective memory tasks that appear to be timebased may in reality be performed as event-based - individuals may rely on environmental cues to prompt them to make a timely response. Setting an alarm clock is a common example, though not a strategy that can be applied in many situations. Another example is maintaining a daily 
calendar and developing the habit of checking it periodically (this itself is a form of time-based prospective memory) or after completing each task. The latter strategy is of course flawed in that, if an ongoing task takes longer than expected — hardly a rare occurrence — the calendar may not be checked soon enough to remember an appointment.

\section{Monitoring and Concurrent Task Management}

In many workplace situations, skilled operators must manage multiple tasks concurrently, and often this involves performing an ongoing task while periodically shifting attention to one or more other tasks to check their status (Wickens \& McCarley, 2008, chapter nine; Loukopoulos et al., 2009). This is a form of time-based prospective memory, and it also involves task switching, but it differs from most task-switching experimental paradigms in that the operator is not explicitly cued when to make the switch. Also, in most task-switching paradigms, switches are made so frequently that participants are not likely to forget to make a switch. (Studies in these paradigms have focused mainly on the issue of time cost in switching between tasks, as a way to explore cognitive mechanisms involved in switching.)

In many workplace and everyday situations individuals perform ongoing tasks for relatively long periods before switching attention to check the status of other tasks; here the danger is of forgetting to switch attention between tasks, thus these situations can be said to involve prospective memory. I will focus mainly on examples from aviation, a domain my colleagues and I have studied extensively; however, the issues also apply to many other domains, such as medical practice and process control industries.

Some situations allow operators to develop a consistent pattern of switching attention among tasks; for example, pilots develop a consistent pattern of monitoring multiple flight instruments (though this pattern may change as a function of flight profile and what the pilot 
wants the aircraft to do at a given time). In these situations, I argue that monitoring the various flight instruments merges into a single habitual task with closely related subtasks (e.g., monitor attitude indicator, switch gaze to airspeed indicators, back to attitude indicator, switch to altimeter, etc); performance of one subtask triggers execution of the next subtask.

Here I want to focus on a different sort of situation in which tasks cannot be practiced together in a consistent fashion to proficiency. Consider the situation in which the distribution of fuel among an aircraft's fuel tanks has become unbalanced in flight and must be rebalanced by running both engines from the tank with more fuel, instead of feeding each engine from its own fuel tank, and this process takes some minutes, depending on the situation. During this period the pilots are engaged in other tasks, but must periodically monitor the fuel gauges to know when to switch the engines back to their respective fuel tanks. These tasks vary depending on when the fuel imbalance occurs, thus pilots cannot practice switching attention between these tasks and monitoring the fuel gauges consistently or extensively enough for attention switching to become automatic. This situation resembles that in time-based prospective memory experiments, differing mainly in that pilots know only approximately how long fuel transfer will take. Pilots report becoming absorbed in ongoing tasks and forgetting to monitor fuel balancing adequately (Loukopoulos et al., 2009). Relevant to this situation is the experimental finding that participants in time-based prospective memory studies sometimes forget to make the intended response even after having checked the time only seconds before (Harris \& Wilkins, 1982; McDaniel, Einstein, Stout, \& Morgan, 2003).

Automobile driving involves situations sharing aspects studied in task switching and aspects studied in prospective memory. Outside the window visual-motor tasks - steering, interpreting road signs, reacting to movement of other cars and pedestrians - must be integrated 
and are sometimes combined with tasks that move attention inside the vehicle: checking instrument displays, tuning the radio, adjusting climate controls, talking with a passenger, or talking on a cell phone. Some tasks, such as steering and reacting to other cars, are closely related and practiced together consistently enough to fuse into a single task, but other tasks are more vulnerable to prospective memory failures. Drivers become absorbed in driving and forget to monitor for a planned exit, or become absorbed in a cell phone conversation and fail to monitor the visual environment frequently enough to respond to unexpected events such as another car swerving across lanes. This absorption, termed cognitive tunneling, is amplified when the current ongoing task makes high demands on executive functions (Wickens \& McCarley, 2008, p. 153). Note that these situations differ from typical prospective memory laboratory paradigms in that the distinction between an ongoing task and a secondary prospective task is lost - the individual may forget to switch attention in either direction. Nevertheless, these situations are relevant to prospective memory because the individual fully intends to keep attention moving back and forth in a timely fashion and "forgets" to do so when becoming absorbed in one of the tasks.

Part of the challenge of remembering to switch attention among monitoring tasks is that the frequency with which attention must be switched is typically not well defined and varies with the current states of the tasks. Consider a first officer who must look down to revise information in the flight management computer (which might be required when the crew receive a revised departure clearance) while the captain is taxiing the airplane to the runway. While making data entries, the first officer must continue other duties, especially looking up to monitor taxi progress and to guard against errors the captain might make, such as crossing a runway without clearance from ground control. If data entry can be quickly accomplished and if no immediate threats exist 
for the taxi, the first officer may devote all attention to completing data entry quickly, otherwise he or she must switch attention back and forth, making a few keystrokes, looking up, and then returning to data entry. The frequency with which the first officer must shift attention to the outside visual environment is not explicitly defined and varies according to what is happening outside the aircraft. To the limited extent this sort of attention switching has been studied, skilled operators seem able to perform well most of the time, but in high workload situations performance can fall apart (Wickens \& McCarley, 2008, chapter nine; Loukopoulos, et al., 2009). In particular, if unexpected problems with data entry arise, the first officer may unwittingly become absorbed in this task to the neglect of monitoring.

Craik and Bialystok (2006) developed a paradigm to study planning and task management in older adults that balances the respective advantages and disadvantages of laboratory studies and field studies. Participants were given the computer-simulated task of cooking breakfast, which involved starting and stopping cooking five foods so that they were all ready at the same time. An additional task of setting the table further increased demands for managing multiple tasks concurrently. Dependent measures were how close participants came to cooking each food the correct amount of time and how close they came to finish cooking all five foods at the same time.

This paradigm illustrates the close relationship of time-based prospective memory to task switching and concurrent task management. An interesting finding was that, although older participants showed the expected performance decrement associated with reduced executive (frontal lobe) functioning during aging, this decrement could be prevented by strong environment support that cued participants to the current status of each task. 
Currently we lack validated computational models of the mechanisms involved in switching attention in time-based prospective memory that would account for vulnerability to lapses. A computational model that might be adapted for lapses in remembering to perform deferred intentions is the activation-based model of memory for goals (Altmann \& Trafton, 2002; Altmann \& Gray, 2008). This model has already been applied to account for delays in resuming interrupted tasks (Trafton \& Monk, 2007), and I suggest it could be expanded to address failures to resume interrupted tasks altogether and failures to switch attention between concurrent tasks.

An issue of especial importance for both theoretical and experimental research is the ability of skilled operators performing ongoing tasks to remember to switch attention to monitor for very low probability events that, if they occurred, would have high consequence. For example, in light aircraft lacking master caution warning systems, pilots should periodically monitor the engine oil pressure and oil temperature gauges, usually placed well to the side of the flight displays that provide information necessary to control the aircraft in instrument meteorological conditions. Excursions of oil pressure and temperature presage engine failure-a very rare event, but one of considerable import in a single-engine aircraft. Unfortunately, we have neither experimental data nor theoretical models of how operators monitor for low probability, high consequence events. Personal experience suggests that operators find it difficult to maintain monitoring in such situations, perhaps because human attention is inherently biased toward sources of task-relevant information in flux. The issue is compounded because there are no standards for how frequently operators should monitor for very low probability, high consequence events. 


\section{Remembering to Perform Habitual Tasks}

Many tasks in workplace and everyday settings are habitual, in some cases performed so frequently and so consistently that execution is largely automatic; in other cases performed less frequently but often enough to at least become routine, though less automatic. An example of a task that seems to be largely automatic is starting one's car-a typical procedure might be to sit in the driver's seat, fasten the seat belt, insert the ignition key, depress the clutch, turn the ignition key, place the gearshift in forward or reverse, and release the clutch while slightly depressing the accelerator. An example of a routine procedure is taking a medication at a particular time each day; although the sequence of actions may not be as automated as starting a car, it may be performed at a consistent time and place. Clearly the cognitive mechanisms underlying habitual performance are quite different from those of remembering to perform an episodic task (event-based or time-based), and for this reason some authors do not consider habitual tasks to involve prospective memory. However, individuals do forget to perform habitual tasks, sometimes with disastrous consequences (Loukopoulos, et al., 2009), so these situations deserve study.

Much of airline flying is repetitive and explicitly prescribed in formal operating procedures. Habitual tasks are also a substantial part of the work of many other professions, such as medical practice, but prospective remembering in any form has received little study in professions outside aviation (see Grundgeiger \& Sanderson, 2009, and Dembitzer \& Lai, 2003, for a few examples from medicine).

Few laboratory studies have examined habitual prospective remembering, and these have not focused on the mechanisms enabling remembering of habitual tasks. Einstein, McDaniel, Smith, and Shaw (1998) gave participants a sequence of 11 ongoing tasks and, as the prospective 
task, asked them to press a designated key during the last $2 \frac{1}{2}$ minutes of each ongoing task. Repetition errors (pressing the key more than once) increased with later tasks, especially with older participants and under divided attention. This suggests that, as the prospective task became somewhat more habitual, participants had trouble remembering if they had performed it on the current occasion, a form of source monitoring or output monitoring error (memory of past occasions becomes blurred with the most recent occasion).

In a similar study, Vedhara et al. (2004) gave older patients 20 blocks of ongoing task trials in which they were to press the space bar during each block at least $30 \mathrm{sec}$ after the start of the task. Providing an auditory cue or combined auditory and visual cues substantially reduced omission errors but not repetition errors. Also, there was some indication of positive correlation of performance in the laboratory prospective memory paradigm with patients' adherence to taking their diabetes medication.

Both Einstein et al. (1998) and Vedhara et al. (2004) termed their work studies of habitual prospective memory, but it is unlikely that the number of prospective memory trials in these studies was sufficient to establish a strong habit of prospective responding, so we are still lacking empirical research on why skilled operators sometimes forget to perform elements of highly practiced tasks.

Taking daily medications falls somewhere between highly practiced tasks and episodic tasks; it is routine and repetitive yet is not performed with the frequency and consistency required to become highly automatic. Medication adherence is a crucial issue, especially among older patients, but only a few studies have analyzed the cognitive factors involved in this form of prospective remembering (Wilson \& Park, 2008). Park, et al. (1991) studied medication organizers (pill containers with separate compartments for each dose) used by arthritis patients 
and found that only one in three over-the-counter organizers appeared to improve adherence. They suggested that effective organizers may improve adherence, both by structuring patients' behavior and by facilitating their comprehension of the drug regimen.

Habitual prospective remembering demonstrates repetition errors as well as omission errors, however repetition errors may be more a matter of retrospective memory than prospective memory. When a task has been performed consistently many times in a largely automatic fashion, little trace of the most recent episode is recorded in declarative memory, thus in situations in which the status of the task is not clearly revealed by the state of the environment it is difficult for individuals to determine whether they have recently performed the task.

In one sense habitual prospective memory has been studied extensively, though not under that rubric. Considerable experimental evidence indicates that, with extensive practice of tasks, action schemata develop, stored as procedural memory (Norman \& Shallice, 1986; Wood \& Neal, 2007). These schemata are activated (retrieved) by associated environment cues and fire off sequential steps of the task automatically. Execution of each step is triggered by performance of the preceding step.

This theoretical account of action schema may help explain why individuals sometimes forget to perform elements of habitual tasks. Forgetting to perform habitual task elements is often associated with interruptions and with circumstances that force pilots to perform elements out of the normal sequence or to defer an element to a later time (Nowinski, Holbrook, \& Dismukes, 2003; Loukopoulos et al., 2009). These circumstances removed normal environmental cues and broke the chain of triggering of sequential task elements. However, these observations came from ethnographic study and analysis of incident and accident reports; controlled studies are needed to verify these impressions and to elucidate underlying mechanisms. 


\section{Substituting Atypical Actions for Habitual Behaviors}

Most of us have had the experience of going into a room intending to perform some action and, distracted by rumination, performing a habitual task instead of the intended task-for example, going into the bathroom to look for a comb and brushing our teeth instead. Reason (1990, pp. 68-71) describes numerous examples of such habit intrusion. It seems likely that when we start out to perform a task similar in initial steps to a habitual task it is easy for our minds to wander and fail to exercise the executive control necessary to prevent a habitual action schema from capturing our actions. In workplace settings in which task steps are performed repetitively in a fixed sequence habit intrusion can be an insidious threat. Also, Betsch, Haberstroh, Molter, and Glockner (2004) found (in a laboratory paradigm) that inadvertently reverting to a routine action rather than substituting an intended alternative action increased substantially under time pressure to perform ongoing tasks.

Substituting atypical actions for habitual behaviors has received little attention from the prospective memory research community, perhaps because these tasks may seem to involve attention and action more than memory. However, these tasks have the essential aspect of requiring the individual to remember to perform a deferred intention (substituting an atypical action for a habitual one) without explicit prompting. Stone, Dismukes, and Remington (2001) designed a paradigm mimicking air traffic control in which participants had to advance several aircraft in a display along a routine (default) path, but occasionally had to remember to direct one aircraft to a non-routine location. Remembering to execute the deferred intention to act against habit was impaired by high workload.

Kvavilashvili (1998) developed a novel paradigm that could be used to study this topic. In this paradigm, participants were given text to read aloud and told to substitute a synonym for a 
given word whenever it was encountered. (In this study detective was substituted for prefect. Participants were Georgians and the text was in Georgian.) Pronouncing familiar words while reading aloud is practiced to such a degree that it is largely automatic, thus participants had to remember without prompting to inhibit the habitual response to the word prefect and substitute the word detective. Failing to substitute words could be regarded as a case of habit intrusion.

One interesting finding of this study was a change in prospective memory failures from the first 10 trials to the last 10 trials. One might expect that performance would improve over the course of the experiment as participants gained experience in inhibiting the habitual response and substituting the atypical response. Surprisingly, the opposite occurred: performance declined during the course of the experiment. Apparently participants became more absorbed in the plot of the story and thus more vulnerable to habit capture.

As an aside, absorption in an ongoing task is a factor that may be of considerable importance in prospective remembering. Absorption (which might also be called "engagement" or "cognitive tunneling") has been studied to some extent in the context of multitasking (Wickens \& McCarley, 2008, p. 153), but it has not been studied in the context of prospective memory, perhaps because of the difficulty of creating objective measures. Conceivably, prospective memory performance in the Kvavilashvili (1998) paradigm might provide such a measure; unfortunately, later research has not followed up on this promising paradigm.

\section{Interruptions}

Work in today's world is rife with interruptions, disrupting performance and causing stress (Lohr, 2007; Monk, Boehm-Davis, \& Trafton, 2004; Trafton \& Monk, 2008). Dodhia and Dismukes (2009) argued that interruptions intrinsically create prospective memory tasks—one must remember to resume the interrupted task after the interruption ends. This may seem easy if 
only the two tasks exist and if environmental cues clearly signal that the interrupted task remains. This is the situation of most experimental studies of interruptions, which focus on the delay in resuming the interrupted task, similar to task switching paradigms (Monk et al., 2004; Trafton, Altmann, Brock, \& Mintz, 2003). However in many everyday situations, interruptions can be prolonged, the suspended state of the interrupted task is not saliently signaled, and new task demands present themselves. Another problem may also occur when the interrupted task is habitual: The individual may confuse the state of the interrupted task with completion on previous occasions or, remembering that the action schema was initiated, assume that it was completed (both are forms of source memory confusion). Procedural memory, enabling execution of habitual tasks, generally does not leave a reliable episodic memory of individual instances of execution.

Interruptions are frequent in the medical field (Chisholm, Collison, Nelson, \& Cordell, 2000; Delucia, Ott, \& Palmieri, 2009; Ebright, Patterson, Chalko, \& Render, 2003; Grundgeiger \& Sanderson, 2009), but few empirical studies have examined the contribution of interruptions to medical error systematically. Grundgeiger, Liu, Sanderson, Jenkins, and Leane (2008) used an interruption event in an anesthesiology simulation involving 12 participants. The habitual prospective memory task was to check that a nurse had verified that a unit of blood to be transfused was the correct type; participants were given an interrupting task at a time they would normally have observed the actions of the nurse setting up the transfusion. The sample size was too small for statistical analysis, but the results suggest that participants who avoided letting the interruption divert their attention were less likely to forget the blood type check or to make it belatedly. This type of study, using realistic simulations to study prospective memory performance of skilled participants, holds considerable promise. 
Dodhia and Dismukes (2009) hypothesized that individuals forget to resume interrupted tasks for three reasons: (1) Interruptions often abruptly divert attention, which may prevent adequate encoding of an intention to resume the interrupted task and forming an implementation plan, (2) new task demands after an interruption's end reduce the opportunity to interpret cues that might remind the individual of the interrupted task, and (3) the transition after an interruption to new ongoing task demands is not distinctive because it is defined conceptually, rather than by a single perceptual cue. Participants were given an everyday ongoing task (at least for college students!) — answering a series of multiple-choice questions — and were told that when interrupted they should return to the interrupted task. However the computer presented a new set of questions immediately after the interruption ended, and participants had to remember without prompting to go back to the interrupted question before proceeding with the new set of questions. Three manipulations improved remembering to resume interrupted questions significantly: providing a reminder at the beginning of the interruption, providing a pause at the beginning of the interruption, and explicitly signaling the end of the interruption. The authors interpreted these results as supporting their hypotheses.

\section{Prospective Remembering in Older Adults}

Researchers have explored prospective remembering in older adults (McDaniel, Einstein, \& Rendell, 2008; Phillips, Henry, \& Martin, 2008; Maylor, 2008), children (Ceci \& Bronfenbrenner, 1985; Kerns, 2000; Kvavilashvili, Kyle, \& Messer, 2008) and several clinical populations (Kliegel, Jager, Altgassen, \& Shum, 2008; Thone-Otto \& Walther, 2008; Kerns \& Price, 2001). I will not review the research on these special populations (the references just cited provide good overviews), but will comment briefly on what is being learned from studies with older adults. Because failures in prospective remembering greatly affect the ability of older 
adults to function independently, much of the early funding for prospective memory came from the U.S. National Institute on Aging and comparable agencies in other countries. Also, researchers have found that aging provides a natural manipulation allowing exploration of the cognitive mechanisms of prospective memory. Many studies have shown that executive functioning, working memory, and attention functions decline in the with advancing age; thus comparing older participants' prospective memory performance with that of younger participants can shed light on the roles of specific cognitive processes.

Early studies of prospective remembering in older adults revealed a paradox: Older participants perform more poorly than younger participants in many laboratory studies but not in many others. And in studies in everyday settings older participants generally perform as well as younger participants — sometimes even better - even though complaining about their memory. McDaniel and Einstein (2000) suggested a resolution of the paradox: Older participants do as well as younger ones in studies using focal cues, for which remembering is argued to be largely automatic; older participants do much worse when non-focal cues are used, making greater demands on executive function, which declines with age. In their own daily environment, some — certainly not all — older adults may benefit from having less demanding ongoing tasks and from incidental reminders in their environment, and may be more likely to employ strategies to bolster prospective remembering.

Helping elderly adults remember to perform daily tasks, such as keeping appointments and taking medicines, is crucial to enable them maintain independent living. Some applied research has been directed to this concern, and it is a topic to which the human factors community has much to contribute (Charness, 2008). In particular, we should draw upon ethnographic studies (Roth \& Patterson, 2004) to create detailed descriptions of the range of 
prospective memory tasks of the elderly and the context in which those tasks must be performed - the living environment and typical ongoing tasks. With these descriptions and with knowledge of older adults' cognitive, perceptual, and physical capabilities, human factors practitioners can design prospective memory aids that are practical and effective.

So, What is Prospective Memory, Really?

Although well-controlled laboratory studies are essential to understanding prospective remembering, we should be cautious in extrapolating findings from these studies because experimental paradigms create conditions not always found in diverse real-world situations. The instructions given participants may lead to more explicit encoding than occurs in some natural situations, and target cues are well defined and fairly simple, whereas in everyday situations the conditions for performing a deferred intention may be ill defined or complex. In everyday settings, incidental cues may remind individuals before, during, or after the time or situation in which they intend to perform a deferred intention. Repeated trials, temporal spacing of trials, short retention intervals, the nature of the ongoing task, and requiring participants to keep in mind as many as six target cues probably affect the interplay of cognitive processes involved in managing the combination of a prospective task with an ongoing task, and these factors may sometimes lead participants to use strategies impractical in everyday life. The factors affecting prospective memory listed in Table 2 seem likely to extrapolate from the laboratory to real-world settings, though empirical research is still needed to evaluate their effectiveness and practicality. Table 3 lists other factors that have as yet received little study but which should be investigated to better understand how prospective remembering functions in everyday and workplace settings.

(INSERT TABLE 3 ABOUT HERE) 
Nevertheless, the research reviewed here, though far from providing a complete story, is a good foundation for understanding prospective remembering. Clearly, it is not a unitary cognitive process, and memory processes are only part of the story. Planning, attention, task switching, and task management are also central players. This is not surprising, given that prospective memory is defined not in cognitive terms but as a practical task: To remember to perform a planned action without prompting at a later time, when we will be occupied with other tasks. How prospective remembering is accomplished and how different cognitive processes come into play are functions of the nature and perceived importance of the intention, whether the individual thinks he or she might forget to perform the intended action, strategies the individual may use to support remembering, how the intention is encoded, the length of the retention interval, and the character of ongoing tasks - especially how those tasks direct attention and cause environmental information to be processed. Researchers should beware of assuming that results obtained in a single experimental paradigm capture the essential nature of prospective remembering. The multi-process theory is a step toward acknowledging the flexibility and diversity of prospective remembering, but even it addresses only some aspects.

One of the early questions in prospective memory research was whether prospective remembering involves specialized functions distinct from those found in the broader field of cognition (Brandimonte et al., 1996). Although our understanding of prospective memory is still incomplete, considerable progress has been made by framing accounts in terms of already known cognitive processes (not limited to memory); as yet it has not been necessary to posit any unique process for prospective memory. Even the intention superiority effect can be described in terms of existing concepts, such as activation and inhibition. But, clearly, prospective remembering is a 
heterogeneous phenomenon, and the challenge is to uncover how multiple cognitive processes come into play in specific situations.

People sometimes assume that forgetting to perform an important task — celebrating a spouse's birthday, removing an instrument before closing a surgical incision, or setting flaps for takeoff-reveals a lack of concern, vigilance, or skill on the part of the person who forgets. But our research with skilled airline pilots reveals that even the most skilled of operators are vulnerable to occasional lapses, even when the lapse threatens their own lives (Loukopoulos et al., 2009). Although research on prospective memory is far from complete, it is now clear that a cognitive account is far more appropriate and useful than moral explanations.

To summarize, the research to date suggests four central aspects of prospective remembering: (1) It can be accounted for in terms of general cognitive mechanisms rather than requiring a unique underlying process, (2) the way these cognitive mechanisms come into play varies substantially with the specific character of the prospective task, ongoing tasks, environmental conditions, and the individual, (3) cueing (external or generated by the individual's stream of thought) is central to retrieval of intentions, and (4) encoding is also crucial, though less studied than cueing.

\section{Measures to Improve Prospective Remembering}

Several authors have suggested ways individuals can reduce vulnerability to forgetting to perform deferred intentions (McDaniel \& Einstein, 2007, pp. 194-205; Dismukes, 2008;

Loukopoulos et al., 2009, chapter six; Wilson \& Park, 2008; Herrmann, Raybeck, \& Gruneberg, 2002, pp. 151-160). For the most part these suggestions are reasonable extrapolations from studies of how prospective memory works in the laboratory and are sensible, but only a few 
studies have empirically examined the effectiveness of countermeasures and the conditions that determine effectiveness (Walker \& Andrews, 2001).

The human factors community has an important role to play in developing practical countermeasures, testing their effectiveness, and educating user groups. The general approach might be to (1) analyze specific workplaces to determine situations in which problematic prospective memory failures occur and the factors contributing to those failures, (2) when possible, revise operating procedures and systems to reduce prospective memory and concurrent task demands and interruptions, (3) design alerting and warning systems to help individuals keep track of uncompleted tasks, and (4) educating individuals about vulnerability. The specific approaches described next can be employed both by human factors practitioners and individuals in their daily lives (Table 4).

\section{(INSERT TABLE 4 ABOUT HERE)}

\section{Recognizing Vulnerability}

I suggest that the first step toward improving prospective remembering is education. People often underestimate vulnerability to forgetting, perhaps because intentions typically involve simple, familiar actions. They may mistakenly assume that intended actions of profound importance (remembering the sleeping infant in the back of the car) will not be forgotten, and they may assume that skill and conscientiousness are adequate safeguards in such situations. But numerous reports reveal that even the most conscientious of skilled operators sometimes forget intended tasks of great importance. My colleagues and I have read many incident reports from pilots, which I generalize as: "I have been an airline captain for many years and have never before had an incident like this. My peers all regard me as an able pilot and a stickler for 
following procedures exactly. I cannot understand why I forgot to call for flaps to be set, but I will be ever more vigilant against making this error again".

McDaniel and Einstein, (2007, pp. 194-205) start their suggestions for improving prospective remembering with a simple recommendation: If an intention is very important, if at all possible, do not delay performing it. Laboratory studies suggest that, as soon as attention turns to other tasks, individuals become vulnerable to forgetting to perform an intention, sometimes in only a few seconds (Einstein, McDaniel, Williford, Pagan, \& Dismukes, 2003; McDaniel, Einstein, Stout, \& Morgan, 2003). But of course in many situations executing an intention when it is formed is simply not possible.

Understanding that we are all vulnerable to forgetting intentions is only the first step of education. People need to know the circumstances in which they are most vulnerable to forgetting and to know what safeguards might be used in particular situations. Ongoing tasks that make heavy cognitive demands increase vulnerability, and anecdotal accounts suggest that deeply engaging tasks may do the same. We may fail to notice our freeway exit either when driving conditions are severely demanding or when they are so undemanding we drift into mental reverie. Habits can protect or undermine prospective remembering. Many automobiles can be locked on exiting either with a button on the driver's armrest or a key fob. Several times after turning off the ignition I have either put my ignition key down or dropped it without noticing while gathering up items to take into the house and then locked the car with the armrest button, discovering that the key was locked in the car only after I shut the door. Now I have developed the habit of always using the fob, never the armrest button, to lock the car. 


\section{Specific Techniques}

Laboratory research points to several techniques that have considerable potential for improving prospective remembering, but diary studies and observational studies reveal that these techniques sometimes work and sometimes fall short. The effectiveness of techniques hinges on the specific details of deferred intentions, the diverse ongoing tasks performed during the retention interval, and the environmental context. Human factors practitioners' skills in analyzing the characteristics and interplay of tasks and environment can make these techniques more reliable. In general, given that no one technique will guarantee successful performance, it is a good idea when possible to combine several techniques to address different contingencies.

Creating reminder cues can be one of the most powerful prospective memory tools. Cues that are distinctive, salient, and closely associated with the intention are generally the most effective, however no cue is effective if the task being performed when retrieval is needed does not direct attention to that cue and cause it to be processed. Thus we must think carefully about what we will likely be doing during the window of opportunity for performing the deferred intention. Best of all are cues that physically impede us from continuing an ongoing task during the window of opportunity. Pilots who must suspend execution of a checklist sometimes put the checklist between the throttle levers, which prevents them from advancing the throttles for takeoff without seeing the checklist.

Cues sometimes fail for unexpected reasons. A friend reported putting a book bag she needed to take to work the next morning against the door she normally takes to her car, but on the morning in question happened to exit from another door and forgot the book bag. Some years ago the computer support people in my organization asked us to leave our computers running on Tuesdays so they could back them up. Being well aware of my absent-mindedness I stuck a post- 
it note reminder on the edge of my computer screen. But by the time Tuesday came around I had become so habituated to the post-it that I turned the computer off as usual.

Implementation planning can also be a powerful tool because it combines several strategies: elaboration of encoding, linking of deferred intentions to retrieval cues, and perhaps shifting allocation of attention by emphasizing the importance of the deferred intention. When you form an intention, give some thought to what you are likely to be doing when you expect to perform the intention. Spend some time imagining yourself performing the intention in conjunction with specific ongoing activities, identify environmental cues associated with those activities, and form a mental association between those cues and the intention. Be wary of changes in plans that may prevent the planned encounter with environmental cues, and perhaps identify multiple sets of cues associated with different contingencies.

In health care, providing explicit reminders, such as automated telephone messages, has been shown to improve appointment keeping (Macharia, Leon, Rowe, Stephenson, \& Hayes, 1992; Morrow, Menard, Ridolfo, \& Leirer, 2003). Tasks that are performed frequently, such as taking daily medications, have a special vulnerability in that individuals may confuse the current occasion with many previous occasions in which the task was performed, and this difficulty seems to be exacerbated in older adults. Simple devices, such as pill organizers, can improve prospective remembering, however careful analysis is required to identify the features that make them effective (Park, et al., 1991). Pill organizers guard against both errors of omission and errors of commission by providing an unambiguous indication of whether pills have been taken at each intended time. However, organizers will work only if they are placed where the user will encounter them when needed. (An alternate approach is to equip the organizer with an alarm.) 
Remembering to perform repeated tasks can also be bolstered by linking the task consistently to other tasks, such as brushing your teeth, already strongly established as habits.

Devices, such as automatic shutoff switches for teapots, and features, such as alerts for automobile headlights inadvertently left on, can greatly aid prospective remembering. Many lay people on their own initiative use various prospective memory aids (Walker \& Andrews, 2001). Personal digital assistants (PDAs) are interesting tools, in that they combine features of several traditional memory aids. PDAs have been shown to improve prospective remembering in everyday situations, but they have drawbacks: They sometimes fail; they can be cumbersome to use, especially for the elderly, and many commercial products require substantial effort to learn to use (Herrmann \& Petro, 1990; Herrmann, Yoder, Wells, \& Raybeck, 1996). Low-tech aids, such as post-it notes and appointment calendars, still have value!

Simple mnemonic techniques can sometimes be helpful. Many of us have had the experience of going to a store for several items and forgetting to buy one of them. Usually this is not a retrospective memory failure, because generally we can recall the items if prompted. Simply counting the number of items to buy when planning the visit can aid prospective memory in this situation by allowing us to count the number of items bought and searching memory if the count is short. This, of course, creates a new prospective memory task-remembering to count items purchased—but this can be established as a habit.

Interruptions challenge us to remember to resume the interrupted task. The limited research on this issue suggests we should pause before addressing an interruption to form an implementation plan for returning to the interrupted task when it becomes possible. Performance of habitual tasks is normally quite reliable and does not require special attention, but becomes far less reliable when task elements must be performed out of order and when the external cues that 
normally trigger initiation of the task are for some reason absent. The best advice in these situations is to treat them as episodic prospective memory situations and to employ the strategies just discussed.

Time-based prospective remembering poses special challenges, in part because cueing is limited. One technique is, whenever possible, to convert the time-based intention into an eventbased intention by identifying cues or linking the intention to activities you will likely be performing at the intended time. For longer retention intervals it may be useful to take advantage of spontaneous retrievals during the interval to rehearse and elaborate links between the intention and potential cues.

Little if any research provides support for prospective remembering when individuals must switch attention repeatedly among two or more tasks. However one possibility comes from studies showing that people find it easier to switch attention if the switch is made after completing a subtask rather than in the middle of a subtask - presumably this reduces the difficulty of reinstating the status of resumed tasks. Thus, when encountering situations in which multiple tasks must be managed concurrently, it may be useful to consider how long you can dwell on each task and plan to perform an appropriate number of steps in that task before switching to another task.

\section{Alerting Systems and Checklists}

In some work environments organizational safeguards have evolved to guard against forgetting to perform crucial actions. In aviation, checklists and alerting systems are used extensively. Itemized checklists are integrated into the flow of operating procedures, and undoubtedly save many lives. However, although they are a valuable safeguard against prospective memory errors, checklists are themselves vulnerable to these errors - for example, 
pilots have forgotten to resume interrupted checklists (Loukopoulos et al, 2009). The effectiveness of checklists depends on both on how they are designed and how they are used is used in the operating environment (Degani \& Wiener, 1993; Loukopoulos et al., 2009; Burian, 2006). Checklists should be initiated at relatively low workload periods, and, whenever possible, critical tasks should be anchored to specific and salient events. For example, in aviation it is better to set flaps to takeoff position directly after engine start rather than while the aircraft is taxiing to the runway.

Warning systems alert pilots to forgotten tasks; for example, the ground proximity warning system of modern airliners verbally annunciates "gear" if pilots have failed to lower the landing gear before landing. Perhaps the next generation of aircraft will have intelligent systems that monitor aircraft state and model crew intentions to provide reminders and warnings closely tuned to diverse situations. However designing any system to support prospective remembering should involve a collaboration of designers, domain experts (in this case, pilots) and human factors experts to insure that the system addresses prospective memory vulnerabilities specific to the situation and that the system does not introduce latent error modes.

Medical error causes tens of thousands of deaths every year in the U.S. alone (Bogner, 1994; IOM, 2000). Although few studies have addressed prospective memory errors in medicine, these errors probably play a significant role (Gawande, Studdert, Orav, Brennan, \& Zinner, 2003; Dembitzer \& Lai, 2003). In recent years, leaders in the medical community have been working to adapt safety procedures from aviation, such as checklists, to medical practice. Two barriers have been encountered. One is that medical practice is less standardized than aviation operations. The other barrier is cultural: Some practitioners regard using memory aids as an admission of lack of professional skill (Hales \& Pronovost, 2006). Nevertheless, when implemented in a way to 
obtain "buy-in" from medical practitioners, checklists can improve patient safety substantially. Haynes et al. (2009) reported introduction of checklists for surgical procedures reduced postsurgical complications from $11 \%$ to $7 \%$ and reduced death rate from $1.5 \%$ to $0.8 \%$.

Unfortunately, this study did not report which errors were reduced by the use of checklists, but prospective memory errors were very probably among them. Similarly, bar coding and automated drug distribution systems have been shown to reduce errors in dispensing medication (Morrow, North, \& Wickens, 2009).

Developing effective and practical prospective memory aids in medicine or any other domain requires careful analysis of the prospective memory and ongoing task demands of each specific operational situation, and a good place to start this analysis is with ethnographic studies (Roth \& Patterson, 2004; also see the next section of this chapter). Human factors practitioners are well suited to this approach of analyzing task demands in the context of the physical and cultural environment of workplaces.

\section{A Research Agenda}

Basic research in prospective memory is now a thriving activity on strong theoretical footing, and scientists in this area have clear ideas of research issues (McDaniel \& Einstein, 2007; Kliegel et al., 2008). Much could be gained by extending research on event-based prospective remembering to examine other forms, especially the several forms of time-based prospective remembering, habitual prospective memory tasks, and interruptions. Underlying these other forms are both basic and applied research issues. For example, we have very little understanding of how people switch attention among unrelated tasks in the absence of explicit cueing when the interval between task switches is too long to support active maintenance in working memory. 
We also need theoretical models of how goals for a suspended task are maintained while elements of an unrelated task are being performed. The cognitive architecture ACT-R originally postulated that goals have a privileged status not requiring source activation to be maintained and included the notion of a goal stack in which sub-goals are popped off as completed, triggering the next sub-goal (Anderson \& Lebierre, 1998). More recently, however, Anderson and Douglass (2001) concluded that goals exist in the same form as other memories. We need computational models of prospective remembering couched from this more recent perspective and addressing the interplay of the goals and sub-goals of prospective and ongoing tasks. Several computational models have been proposed for task switching (e.g., Altmann \& Gray, 2008) and multitasking (e.g., Salvucci \& Taatgen, 2008; Meyer \& Kieras, 1997); perhaps these models could be adapted to account for switching from an ongoing task to a prospective task in conditions in which the switching interval is considerably longer than in most task switching studies. At a more applied level, perhaps the framework of situated cognition (Kirlik, 2006) could be used to model how operators monitor the status of concurrent tasks requiring prospective remembering.

In all forms of prospective memory we need to go beyond memory functions and examine the roles of planning, such as in forming implementation intentions, and attention, especially in managing concurrent tasks.

Another suggestion is to resist the temptation to generalize too broadly from one experimental paradigm. Research to date clearly shows that results vary substantially with characteristics such as the nature and number of target cues, length of the retention period, character and number of ongoing tasks, the relative importance of the prospective and ongoing tasks, and differences among individuals. Almost certainly this reflects differences in cognitive processing as a function of strategies individuals use in specific situations (consciously or 
unconsciously). This is hardly surprising, given that humans are exquisitely adaptive and tend to use strategies that minimize effort while satisficing among multiple goals

Although many studies address the issue of whether prospective remembering requires limited cognitive resources (attention and working memory), little research has explored what strategies individuals use to bolster remembering and what cognitive processes underlie those strategies (but see Guynn, 2008, for an account of how monitoring may be accomplished). Einstein and McDaniel (2008) speculated that individuals may be able to regulate their threshold for noticing cues relevant to deferred intentions. If this is true, it might allow individuals to focus intently on an ongoing task to the exclusion of thoughts of other tasks or, alternatively, to broaden awareness and increase sensitivity to concerns beyond the ongoing task. We need research paradigms to explore this sort of possibility and the various strategies that might be used to support prospective remembering in diverse situations.

To address both theoretical and applied issues we need to thoroughly understand the full range of everyday and workplace situations that create prospective memory demands. Ethnographic observations, diary studies, questionnaires, and realistic simulations of workplace scenarios are valuable tools for this, as well as paradigms such as that of Sellen et al. (1997) that provide objective data in actual workplace settings. These tools of course lack the power of wellcontrolled laboratory paradigms, but they are necessary to identify the phenomena that must be addressed in laboratory studies. Research on human performance is most powerful when reductionistic approaches are combined with observations of integrated performance in the actual environment (or realistic simulations of that environment). For example, observations that pilots sometimes forget to resume interrupted tasks in the cockpit led to experimental study of prospective memory tasks created by interruptions (Dodhia \& Dismukes, 2009). 
Because workplace tasks and situations vary substantially in cognitive and organizational features, systematic observation of specific workplace settings would provide valuable data on the types of prospective memory tasks in those specific settings and how individuals respond. This would allow evaluation of the extent to which laboratory phenomena operate in these settings, and it might also uncover new factors. This "needs analysis" would provide a foundation for developing practical countermeasures - measures that work in laboratory settings might not be practical in workplace and daily living settings, and measures that work in one setting may not work in other settings. Loukoupoulos et al. (2009) analyzed the work of airline pilots in this way; similarly, Park and colleagues (1991) analyzed the effectiveness of medication organizers. The domain of medical practice cries out for analysis of prospective memory demands and potential countermeasures to reduce medical error, and many other workplace settings deserve study.

Also, existing laboratory studies have failed to capture the full range of conditions that individuals use to define the window of opportunity for executing an intention. Consider a typical laboratory study in which the target cue is the word cat, occurring occasionally in a series of words in an ongoing task, such as pleasantness rating. This simple target cue, when presented, provides a clearly defined opportunity to execute the intention. Contrast this with an everyday situation in which you intend to call a colleague shortly after arriving at your office the next morning. The "event", arriving at your office, is characterized by multiple elements rather than any single cue - recognizing, unlocking, and opening the door to your office; putting down your briefcase; sitting at your chair, etc-which unfurl over time and which you may not be thinking of as "arriving at the office", since this activity can be performed largely automatically. In visual attention studies, targets defined by conjunction of two variables (e.g., red X's) require much 
more effort to detect in a field of distractors than targets varying on a single dimension (e.g., all red letters in a field of differently-colored letters) (Triesman \& Gelade, 1980). By analogy, prospective remembering might be improved by selecting simple discrete cues to define when to perform an intention rather than situations such as "arriving at the office", defined by conjunction of several factors. This possibility, however, has not been directly studied.

By their nature, laboratory paradigms establish participants' intentions through instructions designed to minimize performance variations other than through explicit manipulations. We do not know to what extent self-generated intentions, formed in the context of an individual's other goals, habits, and preferences, differ from intentions given by an experimenter. Conceivably we might find a self-generation effect comparable to that observed in retrospective memory, in which individuals better remember information if they generate it themselves rather than receiving it passively (Slamecke \& Graf, 1978). We do know that the laboratory environment both strips away some aspects of the natural world and sometimes creates conditions not found outside the lab. A participant in a prospective memory experiment has only the tasks given by the experimenter: perform the ongoing task and execute the prospective response when a target cue is encountered. (Typically the prospective memory task is presented as a secondary or incidental task; this way of couching instructions affects performance, as Kvavilashvili's 1998 data reveal.) The experiment instructions may create and the laboratory environment may help maintain an association between the ongoing task and the delayed intention not often occurring in situations outside the laboratory. Thus we need paradigms to bridge between real-world situations and existing laboratory studies.

In addition to possible differences between self-generated intentions and typical laboratory instructions, we need to consider that individuals integrate their own intentions into 
their larger set of goals and manage these dynamically, shifting priorities in response to new demands and opportunities. For example, in a study aimed at ecological validity, Marsh, Hicks, and Landau (1998) had participants record planned activities at the beginning of a week's period and track execution of those activities. Among the findings were that participants reprioritized intentions during the week and were likely to fulfill intentions for prearranged appointments and intentions involving commitments to other people, but were less successful in fulfilling intentions to arrange appointments, to take or to return things, and similar activities. The study, which also used laboratory tests of retrospective memory and attention, revealed that the participants had accurate meta-cognitive understanding of their abilities and adapted appropriate compensatory strategies. This study demonstrates the value of paradigms that bridge between well-controlled laboratory studies and ecologically valid studies of how people carry out intentions in their daily lives.

Laboratory studies rarely require participants to retain deferred intentions more than an hour, yet in our daily lives we must sometimes remember intentions formed weeks or even months earlier. The mechanisms of retention and retrieval may differ substantially as a function of retention interval. For example, in laboratory studies, intentions may be maintained in working memory to some degree by association with the ongoing task and with the experimental context (this association would provide activation), but this is unlikely for long intervals filled with diverse ongoing tasks. In contrast to most experimental studies, in everyday situations individuals do not always know what task they will be performing when the opportunity to perform a deferred intention arises.

Also, laboratory studies usually present target cues at least several times, but few studies have examined how one retrieval (or failure to retrieve) might affect the probability of a later 
retrieval of an intention (but see Ellis \& Milne, 1996, and McNerney \& West, 2007, for exceptions). Everyday intentions usually involve fairly broad windows of opportunity for execution rather than the few seconds a participant in an experiment has to respond to a target cue. For example, if you intend to give a message to a friend the next time you see him, you have the full length of the encounter to remember your intention. The implications of these differences between laboratory and everyday situations have seldom been explored.

The suggestions in the previous section for enhancing prospective remembering are sensible and derive from experimental research, but little applied research has been conducted to examine how well these suggestions work in diverse real-world situations or to determine what factors influence effectiveness. Research analogous to that of Park et al. (1991) on effectiveness of pill organizers is especially needed for all workplace and everyday settings in which prospective memory failures can have dire consequences. Electronic devices, such as PDAs, can be useful memory aids, but so far their design requires better human factors analysis and engineering (Herrmann et al., 1996). As an example of this type of human factors analysis, Vortac, Edwards, and Manning (1995) studied air traffic controllers' use of flight data strips to remind themselves of pending actions and explored how switching to visual displays that could not be manipulated might affect prospective remembering. Organizations that do adopt measures to protect prospective remembering of critical tasks would do well to collect before and after data for interventions. (Organizations often fail to actually test the expected effect of interventions.)

Prospective memory is by its nature an important issue in human factors, and the human factors community is well constituted to contribute to understanding of prospective remembering and to develop practical ways of enhancing this crucial aspect of human performance. 
Prospective remembering is the product of many cognitive and social functions, the individual's experience and goals, interplay with multiple ongoing tasks, and the environmental context; thus our understanding of it would benefit greatly from the trans-disciplinary approach of human factors. 


\section{References}

Altmann E. M. \& Gray, W. D. (2008). An integrated model of cognitive control in task switching. Psychological Review, 115(3), 602-639.

Altmann, E. M., \& Trafton, J. G. (2002). Memory for goals: An activation-based model. Cognitive Science, 26, 39-83.

Anderson, J. R. (1996). ACT: A simple theory of complex cognition. American Psychologist, 51, 355-365.

Anderson, J. R. \& Lebierre, C. (1998). The atomic components of thought. Mahwah, NJ: Lawrence Erlbaum Associates.

Anderson, J. R. \& Douglass, S. (2001). Tower of Hanoi: Evidence for the cost of goal retrieval. Journal of Experimental Psychology: Learning, Memory, and Cognition, 27, 1331-1346.

Betsch, T., Haberstroh, S., Molter, B. \& Glockner, A. (2004). Oops, I did it again - Relapse errors in routinized decision making. Organizational Behavior and Human Decision Processes, 93(1), 62-74.

Bogner, M. S. (1994). Human error in medicine. Mahwah, NJ: Erlbaum

Brandimonte, M. A. \& Passolunghi, M. C. (1994). The effect of cue-familiarity, cuedistinctiveness, and retention interval on prospective remembering. The Quarterly Journal of Experimental Psychology Section A: Human Experimental Psychology, 47(3), 565-587.

Brandimonte, M., Einstein, G. O., \& McDaniel, M. A. (1996). Prospective memory: Theory and Applications. Mahwah, NJ: Erlbaum.

Burian, B. K. (2006). Aeronautical emergency and abnormal checklists: Expectations and realities. In Proceedings of the Human Factors and Ergonomics Society 50th Annual Meeting, pp. 101-105, San Francisco: CA.

Ceci, S. J. \& Bronfenbrenner, U. (1985). "Don't forget to take the cupcakes out of the oven": Prospective memory, strategic time-monitoring, and context. Child Development, 56, 152164.

Charness, N. (2008). Aging and human performance. Human Factors, 50(3), 548-555.

Chasteen, A. L., Park, D. C., \& Schwarz, N. (2001). Implementation intentions and facilitation of prospective memory. Psychological Science, 12, 457-461. 
Chisholm, C. D., Collison, E. K., Nelson, D. R., \& Cordell, W. H. (2000). Emergency department workplace interruptions: Are emergency physicians "interrupt-driven" and "multitasking"? Academic Emergency Medicine, 7(11), 1239-1243.

Cohen, A. L. \& Gollwitzer, P. M. (2008). The cost of remembering to remember: Cognitive load and implementation intentions influence ongoing task performance. In M. Kleigel, M. A. McDaniel, \& G. O. Einstein (Eds.), Prospective Memory: Cognitive, Neuroscience, Developmental, and Applied Perspectives (pp. 367-390). New York: Taylor \& Francis Group/Lawrence Erlbaum Associates.

Cook, G. I., Marsh, R. L., \& Hicks, J. L. (2004). Associating a time-based prospective memory task with an expected context can improve or impair intention completion. Applied Cognitive Psychology, 19(3), 345-360.

Craik, F. I. M. \& Bialystok, E. (2006). Planning and task management in older adults: Cooking breakfast. Memory \& Cognition, 34, 1236-1249.

d'Ydewalle, G., Bouckaert, D. \& Brunfaut, E. (2001). Age-related differences and complexity of ongoing activities in time- and event-based prospective memory. American Journal of Psychology, 114(3), 411-423.

Degani, A., \& Wiener, E. L. (1993). Cockpit checklists: Concepts, design, and use. Human Factors, 35(2), 345-359. Also available at http://ti.arc.nasa.gov/m/profile/adegani/Cockpit\%20Checklists.pdf .

DeLucia, P. R., Ott, T. E., \& Palmieri, P. A. (2009). Performance in nursing. In F. T. Durso (Ed.), Reviews of human factors and ergonomics, Vol. 5, pp. 1-40. Santa Monica, CA: Human Factors and Ergonomics Society.

Dembitzer, A. \& Lai, E. J. (2003). Images in clinical medicine: Retained surgical instrument. New England Journal of Medicine, 16(348), 228.

Dieckmann, P., Reddersen, S., Wehner, T., \& Rall, M. (2006). Prospective memory failures as an unexplored threat to patient safety: Results from a pilot study using patient simulators to investigate the missed execution of intentions. Ergonomics, 49, (5-6), 526-543.

Dismukes, R. K. (2008). Prospective memory in aviation and everyday settings. In M. Kliegel, M. A. McDaniel. \& G. O. Einstein (Eds.), Prospective memory: Cognitive, neuroscience, developmental, and applied perspectives (pp. 411-428). Hillsdale, NJ: LEA. 
Dismukes, R. K. \& Nowinski, J. L. (2006) Prospective memory, concurrent task management, and pilot error. In A. Kramer, D. Wiegmann, \& A. Kirlik (Eds.) Attention: From Theory to Practice (pp. 225-236)New York: Oxford University Press.

Dockree, P. M. \& Ellis, J. A. (2001). Forming and canceling everyday intentions: Implications for prospective remembering. Memory \& Cognition, 29, 1139-1143.

Dodhia, R. M. \& Dismukes, R. K. (2009). Interruptions create prospective memory tasks. Applied Cognitive Psychology, 23(1), 73-89.

Ebright, P. R., Patterson, E. S., Chalko, B., \& Render, M. L. (2003). Understanding the complexity of registered nurse work in acute care setting. Journal of Nursing Administration, 33(12), 630-638.

Einstein, G. O., Holland, L. J., McDaniel, M. A. \& Guynn, M. J. (1992). Age-related deficits in prospective memory: The influence of task complexity. Psychology \& Aging, 7(3), 471478.

Einstein, G. O., \& McDaniel, M. A. (1990). Normal aging and prospective memory. Journal of Experimental Psychology: Learning, Memory, and Cognition, 16(4), 717-726.

Einstein, G. O., \& McDaniel, M. A. (in press). Prospective memory and what costs do not reveal about retrieval processes: A commentary on Smith, Hunt, McVay, \& McConnell (2007). Journal of Experimental Psychology: Learning, Memory, and Cognition.

Einstein, G. O., \& McDaniel, M. A. (2008). Prospective memory and metamemory: The skilled use of basic attentional and memory processes. Psychology of Learning and Motivation, 48, 145-174. Also in A. Benjamin (Ed.), The psychology of learning and motivation. San Diego, CA: Elsevier.

Einstein, G. O., McDaniel, M. A., Manzi, M., Cochran, B., \& Baker, M. (2000). Prospective memory and aging: Forgetting intentions over short delays. Psychology \& Aging, 15(4), 671-683.

Einstein, G. O., McDaniel, M. A., Richardson, S. L., Guynn, M. J., \& Cunfer, A. R. (1995). Aging and prospective memory: Examining the influence of self-initiated retrieval processes. Journal of Experimental Psychology: Learning, Memory, and Cognition, 21, 996-1007. 
Einstein, G. O., McDaniel, M. A., Smith, R. E. \& Shaw, P. (1998). Habitual prospective memory and aging: Remembering intentions and forgetting actions. Psychological Science, 9, 284288.

Einstein, G. O., McDaniel, M. A., Thomas, R., Mayfield, S., Shank, H., Morrisette, N, \& Breneiser, J. (2005). Multiple processes in prospective memory retrieval: Factors determining monitoring versus spontaneous retrieval. Journal of Experimental Psychology: General, 134(3), 327-342.

Einstein, G. O., McDaniel, M. A., Williford, C. L., Pagan, J. L., \& Dismukes, R. K. (2003). Forgetting of intentions in demanding situations is rapid. Journal of Experimental Psychology: Applied, 9, 147-162

Ellis, J. A. (1996). Prospective memory or the realization of delayed intentions: A conceptual framework for research. In M. Brandimonte, G. O. Einstein, \& M. A. McDaniel (Eds.), Prospective memory: Theory and applications (pp. 1-22). Hillsdale, NJ: LEA.

Ellis J. \& Milne, A. (1996). Retrieval cue specificity and the realization of delayed intentions. Quarterly Journal of Experimental Psychology (A): Human Experimental Psychology, 49(4), 862-887.

Finstad, K., Bink, M., McDaniel, M., \& Einstein, G. O. (2006). Breaks and task switches in prospective memory. Applied Cognitive Psychology, 20, 705-712.

Gawande, A. A., Studdert, D. M., Orav, E. J., Brennan, T. A., \& Zinner, M. J. (2003). Risk factors for retained surgical instruments and sponges after surgery. The New England Journal of Medicine, 348(3), 228-235.

Glicksohn, J., \& Myslobodsky, M. S. (2006). What it takes to remember the future. In J. Glicksohn \& M. S. Myslobodsky (Eds.), Timing the future: The case for a time-based prospective memory (pp. 263-306). London, UK: World Scientific Publishing Company.

Gollwitzer, P. M. (1999). Implementation intentions: Strong effects of simple plans. American Psychologist, 54, 493-503.

Gollwitzer, P. M., \& Brandstätter, V. (1997). Implementation intentions and effective goal pursuit. Journal of Personality and Social Psychology, 73, 186-199.

Gollwitzer, P. M. \& Cohen, A. H. (2008). Commentary: Goals and the intentions meant to fulfill them. Prospective memory: Cognitive, neuroscience, developmental, and applied perspectives (pp. 433-439). Hillsdale, NJ: LEA. 
Goschke, T. \& Kuhl, J. (1993). Representation of intentions: Persisting activation in memory. Journal of Experimental Psychology: Learning, Memory, and Cognition, 19(5), 1211-1226.

Graf, P. \& Grondin, S. (2006). Time perception and time-based prospective memory. In J. Glicksohn \& M. S. Myslobodsky (Eds.), Timing the future: The case for a time-based prospective memory (pp. 1-24) . London, UK: World Scientific Publishing Company. Grundgeiger, T., Liu, D., Sanderson, P. M., Jenkins, S., \& Leane, T. (2008). Effects of interruptions on prospective memory performance in anesthesiology. In Proceedings of the Human Factors and Ergonomics Society 52nd Annual Meeting, 52(12), 808-812.

Grundgeiger, T. \& Sanderson, P. (2009). Interruptions in healthcare: Theoretical views. International Journal of Medical Informatics, 78(5), 293-307.

Guynn, M. J. (2008). Theory of monitoring in prospective memory: Instantiating a retrieval mode and periodic target checking. Prospective memory: Cognitive, neuroscience, developmental, and applied perspectives, (pp. 53-72). Hillsdale, NJ: LEA.

Guynn, M. J., McDaniel, M. A., \& Einstein, G. O. (1998). Prospective memory: When reminders fail. Memory \& Cognition, 26(2), 287-298.

Guynn, M. J., McDaniel, M. A., \& Einstein, G. O. (2001). Remembering to perform actions: A different type of memory? In H. D. Zimmer, R. L. Cohen, M. J. Guynn, J. Engelkamp, R. Kormi-Nouri, \& M. A. Foley (Eds.), Memory for action: A distinct form of episodic memory? (pp. 25-48). New York: Oxford.

Hales, B. M. \& Pronovost, P. J. (2006). The checklist-A tool for error management and performance improvement. Journal of Critical Care, 21, 231-235.

Harris, J. E. (1984). Remembering to do things: A forgotten topic. In J. E. Harris \& P. E. Morris (Eds.), Everyday memory: Actions and absent-mindedness, (pp. 71-92). London: Academic Press.

Harris, J. W. \& Wilkins, A. J. (1982). Remembering to do things: A theoretical framework and an illustrative experiment. Human Learning, 1, 123-136.

Haynes, A. B., Weiser, T. G., Berry, W. R., Lipsitz, S. R., Breizat, A. S., Dellinger, E. P, et al., (2009). A surgical safety checklist to reduce morbidity and mortality in a global population. New England Journal of Medicine, 360 (5), 491-499.

Herrmann, D. J., \& Petro, S. J. (1990). Commercial memory aids. Applied Cognitive Psychology, 4(6), 439-450. 
Herrmann, D., Raybeck, D., \& Gruneberg, M. (2002). Improving memory and study skills: Advances in theory and practice. Seattle, WA: Hogrefe and Huber Publishers.

Herrmann, D., Yoder, C. Y., Wells, J. \& Raybeck, D. (1996). Portable electronic scheduling/reminding devices. Cognitive Technology, 1, 36-44.

Hicks, J. L., Marsh, R. L., \& Russell, E. J. (2000). The properties of retention intervals and their affect on retaining prospective memories. Journal of Experimental Psychology: Learning, Memory, and Cognition, 26(5), 1160-1169.

Holbrook, J. B. \& Dismukes, R. K. (2009). Prospective memory in everyday tasks. In Proceedings of the Human Factors and Ergonomics Society 53rd Annual Meeting, pp. 590594.

Holbrook, J. B., Nowinski, J. L., \& Dismukes, R. K. (2005, July). Do intentions linger after a prospective memory task has been performed? Presentation at the 2 nd International Conference on Prospective Memory, Zurich, Switzerland.

Hockey, G. R. J., Wastell, D. G. \& Sauer, J. (1998). Effects of sleep deprivation and user interface on complex performance: A multilevel analysis of compensatory control. Human Factors, 40(2), 233-253.

Institute of Medicine (2000). To Err Is Human: Building a Safer Health System. Washington, DC: National Academy Press.

Kerns, K. A. (2000). The CyberCruiser: An investigation of development of prospective memory in children. Journal of the International Neuropsychological Society, 6, 62-70.

Kerns, K. A. \& Price, K. J. (2001). An investigation of prospective memory in children with ADHD. Child Neuropsychology, 7(3), 162-171.

Kirlik, A. (2006). Adaptive perspectives on human-technology interaction: Methods and models for cognitive engineering and human-computer interaction. New York: Oxford University Press.

Kliegel, M., Jager, T., Altgassen, M. \& Shum, D. (2008). Clinical neuropsychology of prospective memory. In M. Kliegel, M. A. McDaniel, \& G. O. Einstein (Eds.), Prospective memory: Cognitive, neuroscience, developmental, and applied perspectives (pp. 283-308). Mahwah: Erlbaum. 
Kliegel, M., Martin, M., McDaniel, M. A., \& Einstein, G. O. (2001). Varying the importance of a prospective memory task: Differential effects across time- and event-based prospective memory. Memory, 9, 1-11.

Kliegel, M., Martin, M., McDaniel, M. A., \& Einstein, G. O. (2002). Complex prospective memory and executive control of working memory: A process model. Psychologische Beitrage, 44, 303-318.

Kliegel, M., Martin, M., McDaniel, M. A., \& Einstein, G. O. (2004). Importance effects on performance in event-based prospective memory tasks. Memory, 12(5), 553-561.

Kliegel, M., McDaniel, M. A., \& Einstein, G. O. (2000). Plan formation, retention, and execution in prospective memory: A new approach and age-related effects. Memory and Cognition, 28(6), 1041-1049.

Kliegel, M., McDaniel, M. A., \& Einstein, G. O. (2008). Prospective memory: Cognitive, neuroscience, developmental, and applied perspectives. New York: Taylor \& Francis Group/Lawrence Erlbaum Associates.

Kvavilashvili, L. (1998). Remembering intentions: Testing a new method of investigation. Applied Cognitive Psychology, 12(6), 533-554.

Kvavilashvili, L. \& Ellis, J. (1996). Varieties of intention: Some distinctions and classification. In M. Brandimonte, G. O. Einstein, \& M. A. McDaniel (Eds.), Prospective memory: Theory and applications (pp. 23-51). Hillsdale, NJ: LEA.

Kvavilashvili, L. \& Fisher, L. (2007). Is time-based prospective remembering mediated by selfinitiated rehearsals? Role of incidental cues, ongoing activity, age, and motivation. Journal of Experimental Psychology: General, 136(1), 112-132.

Kvavilashvili, L., Kyle, F., \& Messer, D. J. (2008). The development of prospective memory in children: Methodological issues, empirical findings and future directions. In M. Kliegel, M.

A. McDaniel, \& G. O. Einstein (Eds.), Prospective memory: Cognitive, neuroscience, developmental, and applied perspectives, (pp. 115-140). Mahwah, NJ: Erlbaum.

Loft, S., Kearney, R. \& Remington, R. (2008). Is task interference in event-based prospective memory dependent on cue presentation? Memory \& Cognition, 36(1), 139-148.

Loft, S. \& Yeo, G. (2007). An investigation into the resource requirements of event-based prospective memory. Memory \& Cognition, 35(2), 263-274. 
Lohr, S. (2007, March 25). Slow down, brave multitasker, and don't read this in traffic. New York Times. Retrieved July 30, 2009, from http://www.nytimes.com/2007/03/25/business/25multi.html?_r=2\&pagewanted=all

Loukopoulos, L. D., Dismukes, R. K., \& Barshi, I. (2009). The multitasking myth: Handling complexity in real-world operations. Aldershot, UK: Ashgate.

Macharia, W. M., Leon, G., Rowe, B. H., Stephenson, B.J., \& Haynes, R. B. (1992). An overview of interventions to improve compliance with appointment keeping for medical services. Journal of the American Medical Association, 267(13), 1813-1817.

Marsh, R. L., Cook, G. I., \& Hicks, J. L. (2006). An analysis of prospective memory. In B. H. Ross (Ed.), The Psychology of Learning and Motivation, Vol. 46 (pp. 115-153). San Diego: Elsevier Academic Press.

Marsh R. L. \& Hicks J. L. (1998). Event-based prospective memory and executive control of working memory. Journal of Experimental Psychology: Learning, Memory, and Cognition, 24(2), 336-349.

Marsh, R. L., Hicks, J. L., \& Bink, M. L. (1998). Activation of completed, uncompleted, and partially completed intentions. Journal of Experimental Psychology: Learning, Memory, and Cognition, 24, 350-361.

Marsh, R. L., Hicks, J. L., \& Byran, E. (1999). The activation of unrelated and cancelled intentions. Memory \& Cognition, 27, 320-327.

Marsh, R. L., Hicks. J. L., \& Cook, G. I. (2005). On the relationship between effort toward an ongoing task and cue detection in event-based prospective memory. Journal of Experimental Psychology: Learning, Memory, \& Cognition, 31(1), 68-75.

Marsh, R. L., Hicks, J. L., \& Cook, G. I. (2006). Task interference from prospective memories covaries with contextual associations of fulfilling them. Memory \& Cognition, 34, 10371045 .

Marsh, R. L., Hicks, J. L., Cook, G. I., Hansen, J. S., \& Pallos, A. L. (2003). Interference to ongoing activities covaries with the characteristics of an event-based intention. Journal of Experimental Psychology: Learning, Memory, \& Cognition, 29(5), 861-870.

Marsh, R. L., Hicks, J. L., Cook, G. I., \& Mayhorn, C. B. (2007). Comparing older and younger adults in an event-based prospective memory paradigm containing an output monitoring component. Aging, Neuropsychology, and Cognition, 14(2), 168-188. 
Marsh, R. L., Hicks, J. L. \& Landau, J. D. (1998). An investigation of everyday prospective memory. Memory \& Cognition, 26(4), 633-643.

Maylor, E. A. (1993). Aging and forgetting in prospective and retrospective memory tasks. Psychology and Aging, 8(3), 420-428.

Maylor, E. A. (2008). Commentary: Prospective memory through the ages. In M. Kliegel, M. A. McDaniel, \& G. O. Einstein (Eds.), Prospective memory: Cognitive, neuroscience, developmental, and applied perspectives, (pp. 217-233). New York: Erlbaum.

McDaniel, M. A. \& Einstein, G. O. (2000). Strategic and automatic processes in prospective memory retrieval. Applied Cognitive Psychology, 14, 127-144.

McDaniel, M. A. \& Einstein, G. O. (2007). Prospective memory: An overview and synthesis of an emerging field. Thousand Oaks, CA: Sage

McDaniel M. A., Einstein G. O. \& Rendell P. G. (2008). The puzzle of inconsistent declines in prospective memory: A multiprocess explanation. In: M. Kliegel, M. A. McDaniel, \& G. O. Einstein (Eds.), Prospective memory (pp. 141-160). New York: Erlbaum.

McDaniel, M. A., Einstein, G. O., Stout, A. C., \& Morgan, Z. (2003). Aging and maintaining intentions over delays: Do it or lose it. Psychology and Aging, 18,823-835.

McDaniel, M. A., Guynn, M. J., Einstein, G. O., \& Breneiser, J. (2004). Cue-focused and reflexive-associative processes in prospective memory retrieval. Journal of Experimental Psychology: Learning, Memory, \& Cognition, 30, 605-614.

McDaniel, M. A., Howard, D. C., \& Butler, K. M. (2008). Implementation intentions facilitate prospective memory under high attention demands. Memory \& Cognition, 36, 716-724.

McDaniel, M. A., Robinson-Riegler, R., \& Einstein, G. O. (1998). Prospective remembering: Perceptually driven or conceptually driven processes? Memory \& Cognition, 26(1), 121 134.

McDonald-Miszczak, L., Gould, O. N., \& Tychynski, D. (1999). Metamemory predictors of prospective and retrospective memory performance. The Journal of General Psychology, 126(1), 37-52.

McNerney, M. W. \& West, R. (2007). An imperfect relationship between prospective memory and the prospective interference effect. Memory \& Cognition, 35, 275-282.

Meacham, J. A. \& Leiman, B. (1976). Remembering to perform future actions. Paper presented at the meeting of the American Psychological association, Chicago, September. Also in U . 
Neisser (Ed.), Memory observed: Remembering in natural contexts, (pp. 327-336). San Francisco, CA: W. H. Freeman and Company.

Meeks, J. T., \& Marsh, R. L. (2010). Implementation intentions about nonfocal event-based prospective memory tasks. Psychological Research, 74(1), 82-9.

Meyer, D. E., \& Kieras, D. E. (1997). A computational theory of execution cognitive processes and human multiple-task performance: Part 1. Basic mechanisms. Psychological Review, 104(1), 3-65.

Miller, G. A., Galanter, E., \& Pribram, K. H. (1960). Plans and the structure of behavior. New York, NY: Holt, Rinehart and Winston.

Milne, S.E., Orbell, S. \& Sheeran, P. (2002). Combining motivational and volitional interventions to promote exercise participation: Protection motivation theory and implementation intentions. British Journal of Health Psychology, 7, 163-184.

Monk, C., Boehm-Davis, D. A., \& Trafton, J. G. (2004). Recovering from interruptions: Implications for driver distraction research. Human Factors, 46(4), 650-663.

Morrow D. G., Menard W. E., Ridolfo H. E., \& Leirer V. O. (2003). Arriving prepared: Automated telephone messages improve appointment adherence. Gerontechnology, $2(3): 247-254$.

Morrow, D., North, R., \& Wickens, C. D. (2005). Reducing and mitigating human error in medicine. In R. S. Nickerson (Ed.), Reviews of human factors and ergonomics, Vol. 1, pp. 254-296. Santa Monica, CA: Human Factors and Ergonomics Society.

Nigro, G. \& Cicogna, P. C. (2000). Does delay affect prospective memory performance? European Psychologist, 5(3), 228-233.

Norman, D. A. \& Shallice, T. (1986). Attention to action: Willed and automatic control behavior. In R. H. Davidson, G. E. Schwartz, and D. Shapiro (Eds.), Consciousness and selfregulation, advances in research and theory (pp. 1-18). New York, NY: Plenam.

Nowinski, J. L., Holbrook, J. B., \& Dismukes, R. K. (2003). Human memory and cockpit operations: An ASRS study. In Proceedings of the 12th International Symposium on Aviation Psychology (pp. 888-893). Dayton, OH: The Wright State University.

Nowinski, J. L. \& Dismukes, R. K. (2005). Effects of ongoing task context and target typicality on prospective memory performance: The importance of associative cuing. Memory, 13(6), 649-657. 
Orbell, S., Hodgkins, S., \& Sheeran, P. (1997). Implementation intentions and the theory of planned behavior. Personality and Social Psychology Bulletin, 23(9), 945-95

Park, D. C., Morrell, R. W., Frieske, D., Blackburn, B. A., \& Birchmore, D. (1991). Cognitive factors and the use of over-the-counter medication organizers by arthritis patients. Human Factors, 33(1), 57-67.

Phillips, L. H., Henry, J. D. \& Martin, M. (2008). Adult aging and prospective memory: The importance of ecological validity. In M. Kliegel, M. A. McDaniel \& G. O. Einstein (Eds.), Prospective memory: Cognitive, neuroscience, developmental, and applied perspective (pp. 161-185). NY: Lawrence, Erlbaum.

Reason J. (1990). Human error. New York: Cambridge University Press.

Reese, C. M. \& Cherry, K. E. (2002). The effects of age, ability, and memory monitoring on prospective memory task performance. Aging Neuropsychology and Cognition, 9(2), 98113.

Roth, E. M. \& Patterson, E. S. (2004 ). Using observational study as a tool for discovery: Uncovering cognitive and collaborative demands and adaptive strategies. In $\mathrm{H}$. Montgomery, R. Lipshitz, \& B. Brehmer (Eds.), How professionals make decisions (pp. 379-394). Boca Raton, FL: CRC Press.

Salvucci, D. D., \& Taatgen, N. A. (2008). Threaded cognition: An integrated theory of concurrent multitasking. Psychological Review, 115, 101-130.

Sellen, A. J., Louie, G, Harris, J. E. \& Wilkins, A. J. (1997). What brings intentions to mind? An In Situ study of prospective memory. Memory, 5(4), 483-507.

Sheeren, P. \& Orbell, S. (1999). Implementation intentions and the theory of planned behavior. Personality and Social Psychology Bulletin, 23(9), 953-962.

Slamecka, N. J., \& Graf, P. (1978). The generation effect: Delineation of a phenomenon. Journal of Experimental Psychology: Human Learning and Memory, 4(6), 592-604.

Smith, R. E. (2003). The cost of remembering to remember in event-based prospective memory: Investigating the capacity demands of delayed intention performance. Journal of Experimental Psychology: Learning, Memory, and Cognition, 29(3), 347-361.

Smith, R. E. \& Bayen, U. J. (2004). A multinomial model of event-based prospective memory. Journal of Experimental Psychology: Learning, Memory, and Cognition, 30(4), 756-777. 
Smith, R. E., Hunt, R. R., McVay, J. C. \& McConnell, M. D. (2007). The cost of event-based prospective memory: Salient target events. Journal of Experimental Psychology: Learning, Memory, \& Cognition, 33(4), 734-746.

Stone, M., Dismukes, R. K., \& Remington, R. W. (2001). Prospective memory in dynamic environments: Effects of load, delay, and phonological rehearsal. Memory, 9(3), 165-176.

Thone-Otto, A.I.T. \& Walther, K. (2008). Assessment and treatment of prospective memory disorders in clinical practice. In M. Kliegel, M. A. McDaniel, and G. O. Einstein (Eds.), Prospective Memory: Cognitive, neuroscience, developmental, and applied perspectives. New York: Laurence Erlbaum.

Trafton, J. G., Altmann, E. M., Brock, D. P., \& Mintz, F. E. (2003). Preparing to resume an interrupted task: Effects of prospective goal encoding and retrospective rehearsal. International Journal of Human-Computer Studies, 58, 583 - 603.

Trafton, J. G., \& Monk, C. M. (2007). Task Interruptions. In D. A. Boehm-Davis (Ed.), Reviews of Human Factors and Ergonomics, Volume 3, 111-126. Santa Monica, CA: Human Factors and Ergonomics Society.

Treisman, A., \& Gelade, G., 1980. A feature integration theory of attention. Cognitive Psychology, 12, 97-136.

Uttl, B. (2005). Age-related changes in event cued prospective memory proper. In N. Ohta, C. M. MacLeod, \& B. Uttl (Eds.), Dynamic cognitive processes (pp. 273-303). Tokyo: Springer-Verlag.

Vedhara, K., Wadsworth, E., Norman, P., Searle, A., Mitchell, J., Macrae, N., O’Mahony, M., Kemple, T., \& Memel, D. (2004). Habitual prospective memory in elderly patients with Type 2 diabetes: Implications for medical adherence. Psychology, Health and Medicine, 9(1), 17-27.

Vortac, O. U., Edwards, M., \& Manning, C. A. (1995). Functions of external cues in prospective memory. Memory, 3, 201-219.

Walker, W. R. \& Andrews, R. Y. (2001). External memory aids and the use of personal data assistants in improving everyday memory. International Journal of Cognitive Technology, 6(2), 15-25.

Wichman, H. \& Oyasato, A. (1983). Effects of locus of control and task complexity on prospective remembering. Human Factors, 25(5), 583-591. 
Wickens, C. D. \& McCarley, J. S. (2008). Applied attention theory. Boca Raton, FL: Taylor \& Francis.

Wilson, E. A. H. \& Park, D. (2008). Prospective memory and health behaviors: Context trumps cognition. In M. Kliegel, M. A. McDaniel, and G. O. Einstein (Eds.), Prospective Memory: Cognitive, neuroscience, developmental, and applied perspectives (pp. 391-407). New York: Laurence Erlbaum.

Wood, W. \& Neal, D. T. (2007). A new look at habits and the habit-goal interface. Psychological Review, 114(4), 843-863. 


\section{Appendix}

LDT is a speeded task, which may affect how participants allocate resources, and more than one interpretation of LDT slowing is possible. For example, it might be that cognitive resources are required to be prepared on all trials to inhibit speeded responses to the LDT in case a prospective memory target appears. Further, I suggest that cost to an ongoing task may not always represent operation of an attentional state, but could in some circumstances be a memory process consistent with automatic retrieval. In typical laboratory paradigms, the goal of performing the ongoing task and the goal of performing the prospective task are linked and are sub-goals of the super-ordinate goal of following all of the experimenter's instructions. Attending to the ongoing task would provide activation, not just to the elements of the ongoing task, but also to the associated prospective task. This division of activation - an example of the fan effect—would reduce available activation for performing ongoing task elements and slow lexical decision-making. Note that this effect would be automatic, and would not involve attention per se. If this argument is correct, we would expect the association between the ongoing task and the prospective task to weaken over time if no prospective trials are encountered, and this would reduce slowing of lexical decision-making, which is exactly what Loft, Kearney, \& Remington (2008) found. 


\section{Acknowledgments}

I thank Barbara Burian, Jon Holbrook, Loukia Loukopoulos, Jessica Nowinski, and four anonymous reviewers for helpful comments on an earlier version of this chapter. This work was funded by NASA's Aviation Safety Program (Kara Latorella, program element manager) and by the FAA (Eleana Edens, program manager). Special thanks to Kim Jobe for invaluable help with literature searching and manuscript preparation. 
Table 1

Varieties of Prospective Memory

\begin{tabular}{|c|c|}
\hline Prospective memory type & Examples \\
\hline Event based & $\begin{array}{l}\text { Intending to give a message to a } \\
\text { friend when next encountered }\end{array}$ \\
\hline Time based & $\begin{array}{l}\text { Intending to take cookies out of the } \\
\text { oven after } 20 \text { minutes }\end{array}$ \\
\hline Time based & $\begin{array}{l}\text { Intending to go to a medical } \\
\text { appointment at 10:00 a.m. }\end{array}$ \\
\hline Switching attention among concurrent tasks & $\begin{array}{l}\text { Driving an automobile while using a } \\
\text { cell phone }\end{array}$ \\
\hline Performing sequential elements of habitual tasks & $\begin{array}{l}\text { Procedure for starting aircraft } \\
\text { engines }\end{array}$ \\
\hline Substituting an atypical action for a habitual one & $\begin{array}{l}\text { Deviating from the habitual route to } \\
\text { work }\end{array}$ \\
\hline Interruptions & Telephone call while cooking a meal \\
\hline
\end{tabular}


Table 2

Variables that Affect Prospective Memory Performance

Variable Effect

Implementation intentions - encoding a Improves performance

specific time and place to perform a

deferred intention and identifying

environmental cues likely to be present.

Cues that are salient, distinctive, unusual or Improves performance

highly related to the prospective task.

Importance of prospective memory task. Can improve performance if it leads

individual to allocate increased attention to

prospective task or adapt compensatory

strategies such as creating reminder cues.

Degree to which ongoing task focuses Improves performance

attention on cues related to the

prospective task.

Degree to which ongoing task causes Improves performance

prospective cues to be processed in the

same manner in which they were encoded. 
Remembrance of Things Future 81

Table 2 (continued).

Variable

Affect

Age

Impairs performance of tasks in which

target cue is not focal—no effect when

target cue is focal.

Divided attention

Impairs performance for some tasks but not

others. 
Table 3

Prospective memory factors for which applied research is needed in everyday and workplace situations

Types of prospective memory tasks encountered in specific settings and the context (e.g., character of ongoing tasks and presence of environmental cues)

How individuals encode various types of deferred intention, including implementation strategies.

Effects of retention intervals ranging from hours to months.

Where and how different types of deferred intentions are maintained during retention: working memory, long-term memory, or cycling between the two?

The role of rehearsal and reminders during retention.

The role of incidental (vs. planned) cues in triggering retrieval of intentions.

The character of the window of opportunity for executing deferred intentions (e.g., defined by occurrence of a single unambiguous cue vs. defined by a combination of factors with a broad time frame).

The effect of self-generated intentions vs. experimenter instructions.

Strategies individuals use to bolster performance in specific situations.

The effects of experience and expertise on performance.

The consequences of holding in memory multiple and diverse intentions awaiting the appropriate circumstances for execution. 
Table 4

Prospective Memory Countermeasures

\section{For designers of systems and procedures:}

Analyze the specific operating environment to identify "hotspots" in which prospective memory and concurrent task demands are high and interruptions are frequent. To the extent possible, re-design procedures and systems to reduce demands, especially when the consequences of memory lapses are high.

In situations in which prospective memory vulnerability is high, design display and alerting systems to help individuals keep track of status of tasks not concurrently active. These systems can range from simple (pill organizers) to sophisticated (takeoff configuration warning systems).

Create checklists and team procedures to catch memory lapses.

Educate individuals and managers about prospective memory vulnerability and point out countermeasures individuals can take.

\section{For individuals:}

Avoid deferring crucial tasks when possible.

Form implementation intentions. 
Table 4 (continued).

Create reminder cues and place them where they are likely to be encountered when the deferred task is to be performed. Choose cues that are salient, distinctive, unusual, and/or highly related to the prospective task.

When interrupted, pause to encode an explicit intention to resume the interrupted task after the interruption ends.

Minimize trying to juggle multiple tasks concurrently if one of the tasks in vital. In particular, do not use cell phones while driving.

Link prospective memory tasks to well-established habits, such as brushing teeth.

When elements of habitual tasks must be performed out of sequence, treat these as eventbased prospective memory situations and create reminder cues.

Use external memory aids such as post-its, daily calendars, and PDA's. 


\section{Figure Caption}

Figure 1. PsychInfo was searched for papers in which the terms "prospective memory" or "prospective remembering" appeared in the title or abstract. Data are plotted in two-year increments. This number may be an undercount because some reports may use terms other than these two, e.g., "remembering deferred intentions". 
Figure 1: Number of Prospective Memory Papers Published by Year

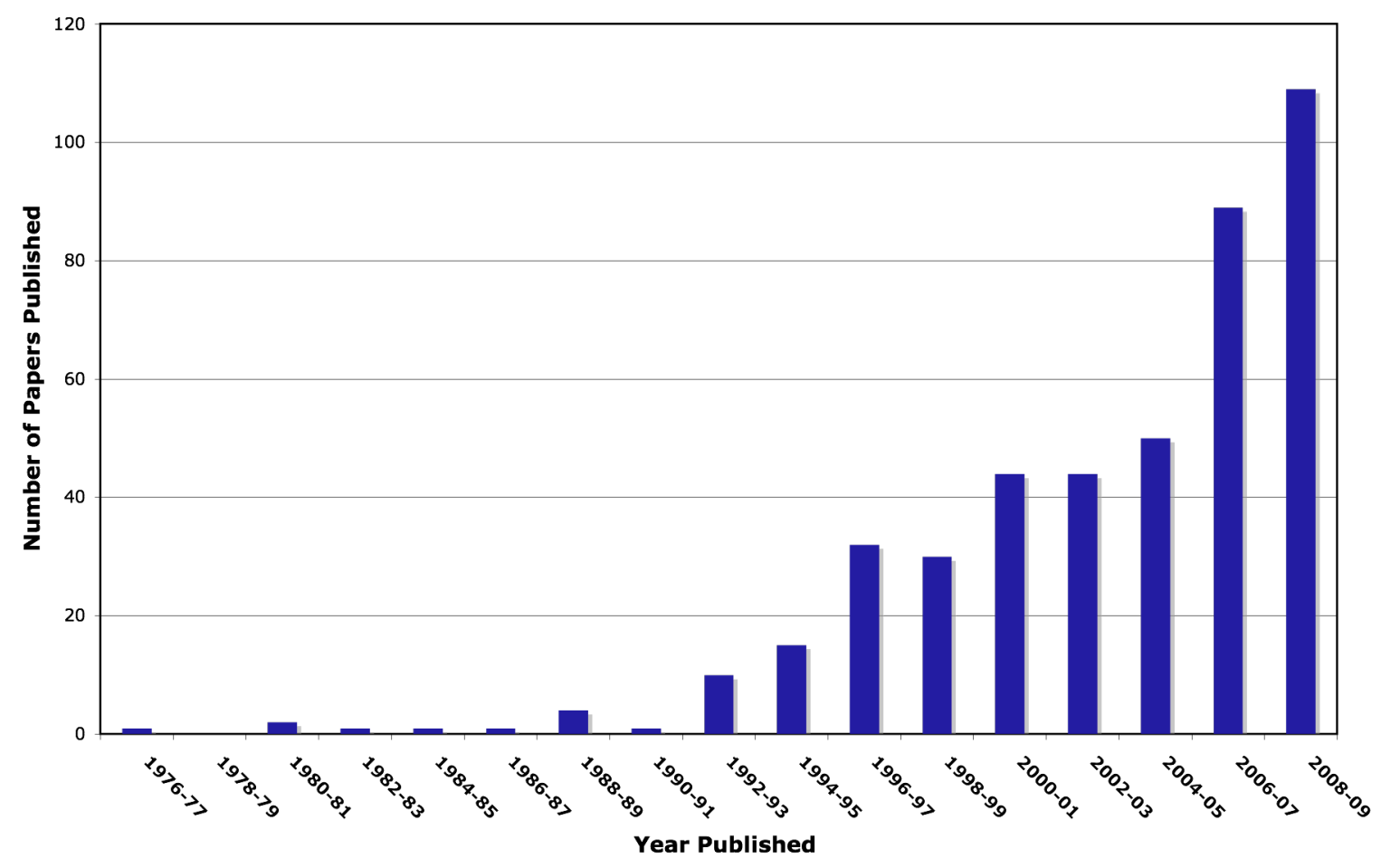

